\title{
Direct Laser Metal Deposition (DLMD) Additive Manufacturing (AM)of Inconel 718 Superalloy: Elemental, Microstructural and Physical Properties Evaluation
}

\author{
Mahmoud Moradi ( $\square$ ad6683@coventry.ac.uk) \\ Coventry University \\ Zeynab Pourmand \\ Malayer University \\ Arman Hasani \\ Malayer University \\ Mojtaba Karami Moghadam \\ Malayer University \\ Amir Hosein Sakhaei \\ University of Kent \\ Mahmood Shafiee \\ University of Kent \\ Jonathan Lawrence \\ Coventry University
}

\section{Research Article}

Keywords: Additive Manufacturing (AM), Direct Laser Metal Deposition (DLMD), Inconel 718 Superalloy, Dimensional Stability, Microstructure.

Posted Date: May 18th, 2021

DOI: https://doi.org/10.21203/rs.3.rs-455976/v1

License: (9) This work is licensed under a Creative Commons Attribution 4.0 International License. Read Full License

Version of Record: A version of this preprint was published at Optik on March 1st, 2022. See the published version at https://doi.org/10.1016/j.ijleo.2022.169018. 


\title{
Direct Laser Metal Deposition (DLMD) Additive Manufacturing (AM)of Inconel 718 Superalloy: Elemental, microstructural and physical properties evaluation
}

\author{
Mahmoud Moradi ${ }^{1 *}$, Zeynab Pourmand ${ }^{2}$, Arman Hasani ${ }^{2}$, Mojtaba Karami \\ Moghadam ${ }^{2}$, Amir Hosein Sakhaei ${ }^{3}$, Mahmood Shafiee ${ }^{3}$, Jonathan Lawrence ${ }^{1}$ \\ ${ }^{1}$ School of Mechanical, Aerospace and Automotive Engineering, Faculty of Engineering, \\ Environment and Computing, Coventry University, Gulson Road, Coventry, CV1 2JH, \\ United Kingdom. \\ ${ }^{2}$ Department of Mechanical Engineering, Faculty of Engineering, Malayer University, \\ Malayer, Iran \\ ${ }^{3}$ Mechanical Engineering Group, School of Engineering, University of Kent, Canterbury \\ CT2 7NL, United Kingdom \\ *Corresponding author email: ad6683@ coventry.ac.uk
}

\begin{abstract}
In this study direct laser metal deposition (DLMD) technique is adopted for the additive manufacturing (AM) of Inconel 718 Superalloy. To conduct the experiments, a $1 \mathrm{~kW}$ fiber laser with a coaxial nozzle head is used. The effects of scanning speed (for two values of 2.5 and 5 $\mathrm{mm} / \mathrm{s}$ ) as well as powder feed rate (for two values of 17.94 and $28.52 \mathrm{~g} / \mathrm{min}$ ) on the process were investigated. Characteristics of the 3D printed wall specimens such as the geometrical dimensions (width and height), microstructure observations, and the microhardness were obtained. In order to study the stability of the 3D manufactured walls, the height stability was considered for the investigation. Optical microscopy (OM), field emission electron microscopy (FE-SEM), energy dispersive X-ray spectroscopy (EDS), and mapping analysis were performed to derive the microstructural features of the additive manufactured samples. The Vickers microhardness test is used to evaluate the hardness distributions of additively manufactured parts. Catchment concept of the powder in DLMD process is used for explaining different trends of the process. Results indicated that, by decreasing the scanning speed, the width and height of the deposited layer increase. The average width of the additively manufactured samples directly depends on the scanning speed and the powder feed rate. Scanning speed has a reverse effect on the height stability; that is, the lower the scanning speed, the larger the stability. Microstructural results showed that because of the solidification process, the alloying elements will be accumulated in the grain boundaries. The non-uniform cooling rate and non-steady solidification rates of molten area in additive manufacturing process, the microhardness values of the additively manufactured samples following a fluctuated trend.
\end{abstract}

Keywords: Additive Manufacturing (AM); Direct Laser Metal Deposition (DLMD); Inconel 718 Superalloy; Dimensional Stability; Microstructure. 


\section{Introduction}

The processes for additive manufacturing (AM), also referred to as 3D printing, have impressive improvements in recent years and companies and institutions have made a fairly competition for expanding the useful aspects of this technology, such as cost, complex geometries, replacement and maintenance [14]. With the development of specialized facilities in AM, and providing superb conditions for the manufacturing the high accuracy and affordable products, it has attracted the attention of many scholars and industries [5-7]. The AM process is also referred to layer production [8-10]. This method is one of the fastest and most reliable manufacturing processes, which is used to create a high quality and accuracy new sample [11]. 3D printing has many advantages over traditional production methods [12]. The production of complex geometries by traditional manufacturing methods is very sophisticated and is not affordable in many cases. A wide range of materials are applied for AM approaches such as plastics, metals, ceramics, and composites [13-16]. The AM technology is divided into different categories based on their approach of printing, equipment or printer devices, materials and etc [17-20]. The laser device is one of the most useful equipment in the industrial applications that have a significant effect on properties of additively manufactured parts [21-24].

The laser AM method is a modern and evolving process, which is capable of many complex components by using a variety of powders, including metals, nonmetallics and composites [25-28]. In AM process by laser, the layers are produced by various input parameters [29-30]. Recently, extensive research has been done in this field of science. Kong et al. [31] investigated the effect of deposition created by laser AM process on non-traditional machining via a high-throughput dual-feed system. Wolff et al. [32] evaluated laser AM by twin feeders where Inconel 718 was used as powder. The goal of this study was that how the cooling rate after AM process can be affected on additively manufactured additively 
manufactured sample's structure. An experimental study from the AM process of Inconel 718 which was shown the sidewall nonuniformity and deposit bulge was performed by Lee et al. [33]. The quality and dimensions accuracy of additively manufactured specimens were studied in references [34-38]. The results showed that this experiment provided some additively manufactured samples with a suitable surface quality. A similiar research about the quality and microhardness trend was conducted by Liu et al. [39]. It is worth mentioning that the Inconel 718 material is one of the most used materials in the manufacturing industry. Shang et al. [40] joined two parts of multi-material objects by the laser AM process. Due to the joining parts of AM process some parts were joined very well. Caiazzo et al. [41] generated some layers by changing nozzle scanning speed and laser power in the Directed Metal Deposition (DMD) method. These parameters have a critical role in AM process because by controlling these inputs the samples were generated very well. Liu et al. [42] investigated Laser Powder Deposition (LPD) method by using the AlSi10Mg alloy and Taguchi approach for the optimization of AM process. Wang et al. [43] studied microstructure of the deposited layer of additively manufactured samples. DLAM method in the laser AM process for biomaterials based titanium and molibden (Ti-15Mo) was studied by Bhardwaj et al. [44]. With this approach, they printed some samples which are usable in human surgery parts. Momenzadeh et al. [45] investigated the simulation and analysis of specific implant, which was printed by the laser AM process. AISI 304L is a very popular stainless steel in the manufacturing process. This material was joined to a Ti- $6 \mathrm{Al}-4 \mathrm{~V}$ with the laser AM process by Reichardt et al. [46]. The deposition layer from the laser AM process via high power diode laser by AISI 316L powder was investigated in Guo et al. [47]. The microstructure of additively manufactured parts shown that the stability between interfaces of layers was a superb joint together.

As the above review shows, the relation between direct laser metal deposition and microstructure effects after AM of super alloys have been addressed. 
However, there are still many areas which have not been considered. By conducting some research, it is clear that, the behavior of the AM process on the microstructure of Inconel 718 is very sophisticated because the cooling rate and controlling the input parameters for generating a high-quality structure is very complicated. Inconel 718 is one of the much usable superalloys which its behavior from the procedures for material processing is very important in industry applications. In the present study, the DLMD process is applied for AM of Inconel 718 nickel-base super-alloy deposited wall on the AISI 4130 alloy steel substrate using a $1 \mathrm{~kW}$ fiber laser. The effects of powder feed rate and scanning speed on geometrical aspects (i.e. height, average of width), microstructural observations and microhardness trend of additively manufactured samples in different layers are investigated. The results are explained by powder catchment ratio concept in DLMD process. Considering the powder catchment ratio concept and studying the geometrical stability of the additively manufactured walls, are relatively new accompaniments to this field.

The organisation of the remainder of this paper is as follows. In Section 2, experimental study of DLMD process and some parameters are discussed such as catchment, stability rate, which are considered as outputs. In Section 3 and 4, results from measurements and conclusions are discussed, respectively.

\section{Experimental details}

\subsection{Experiment materials, apparatus and configuration}

Commercial Inconel 718 powder was used. The particle size of the powder was imaged with a field emission electron microscopy (FE-SEM) (MIRA 1ll; TESCAN) and is shown in Figure 1. 

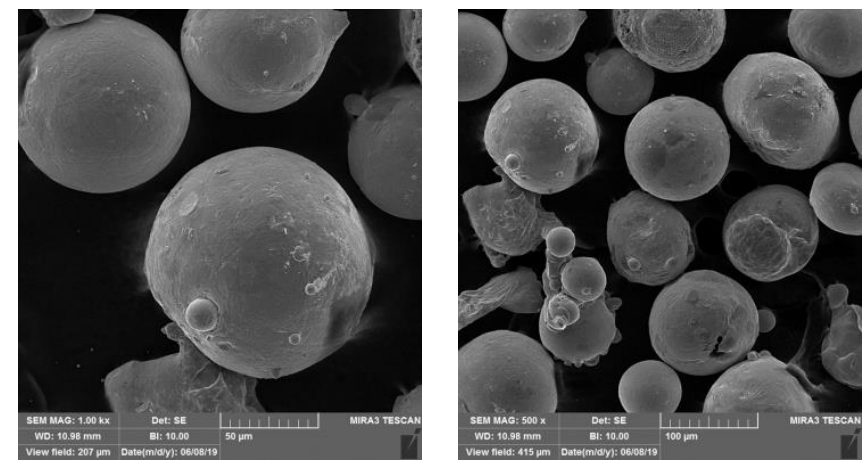

Figure 1 FESEM of Inconel 718 powder.

As can be seen, the particle size of the powder is in the range of 45 to $90 \mu \mathrm{m}$. Due to previous studies and research the size of powder must be in this range. When the size of a particle smaller or larger than 40 to $120 \mu \mathrm{m}$, the quality of additively manufactured additively manufactured samples may be decreased. The chemical compositions for the Inconel 718 powder and the AISI 4130 steel are given in Table 1. AISI 4130 steel was used as a substrate. Inductively coupled plasma spectrometer (ICP) analysis has been applied to obtain powder compounds and quantum test for the percentage of compounds in the substrate. The substrate structure is ferrite-perlite and raw bar for AISI 4130 steel with a thickness of 7 $\mathrm{mm}$ and a diameter of $65 \mathrm{~mm}$.

3. Table 1 Chemical composition (Wt. \%) of Inconel 718 and AISI 4130 steel

\begin{tabular}{ccccccccccc}
\hline Powder & Inconel & Al & Co & $\mathbf{C r}$ & $\mathbf{F e}$ & $\mathbf{M n}$ & $\mathbf{M o}$ & $\mathbf{N b}$ & $\mathbf{N i}$ & $\mathbf{T i}$ \\
\cline { 3 - 12 } & $\mathbf{7 1 8}$ & 0.248 & 0.0768 & 19 & 17.5 & 0.163 & 3.29 & 4.9 & 54 & 0.13 \\
\hline Substrate & AISI & $\mathbf{M o}$ & $\mathbf{C u}$ & $\mathbf{C r}$ & $\mathbf{S}$ & $\mathbf{M n}$ & $\mathbf{S i}$ & $\mathbf{P}$ & $\mathbf{N i}$ & $\mathbf{C}$ \\
& $\mathbf{4 1 3 0}$ & 0.25 & 0.06 & 1.01 & 0.03 & 0.87 & 0.3 & 0.016 & 0.05 & 0.25 \\
\hline
\end{tabular}

The laser used for the DLMD was a $1 \mathrm{~kW}$ Fiber laser (YFL-1000 model made in Iranian National Laser Center) with the minimum spot size of the laser at focal position of $0.2 \mathrm{~mm}$, the focal length of $200 \mathrm{~mm}$, the Rayleigh length of $2 \mathrm{~mm}$ and wave length of $1080 \mathrm{~nm}$ which was operated in continuous wave was used. The laser sourceembedded within a CNC table that moves in three perpendicular directions $(\mathrm{x}, \mathrm{y}, \mathrm{z})$. The table in each direction is moved by Mach3D software that defines a special G-code for each direction of the table. When the table moves 
based on regulated CNC profram, the powder is deposited by the laser beam, and the additively manufactured sample is constructed as shown in Figure 1. The powder supply on the AM process is a twin powder feeder system. The powders are carried out by gas pressure transfers into the feeder and powder inside the vessel.

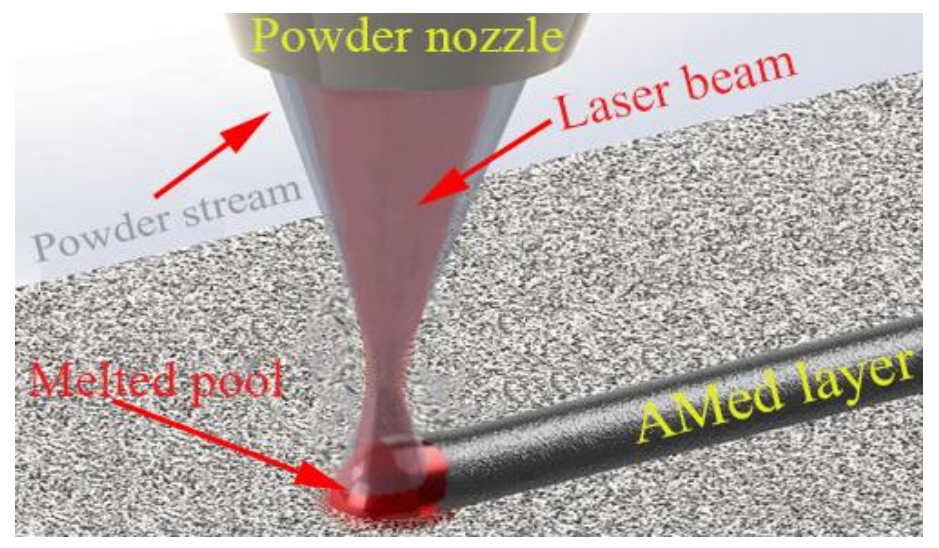

Figure 2 Schematic diagram showing the DLMD configuration [48].

Ar gas was used as a shielding gas as well as the powder carrier gas. In all experiments, axial gas pressure was $31 / \mathrm{min}$, powder carrier gas pressure was 1.5 1/min and $250 \mathrm{~W}$ laser power were considered as constant parameters. The focal plane position (FPP), the number of deposition layers (5 layers), the dwell time of the deposition layers and the continuous laser wave are also considered as fixed parameters. In addition, two parameters of this process, the powder feed rate and CNC table scanning speed are variable. Table 2 presents the values of process input and output parameters.

\subsection{Sample analysis techniques}

After the AM process, the specimens were cut by the wire cut, and their crosssections were etched according to ASTM E 407: 07 by Glyceregia electrochemistry for the metallographic process [49]. The Ws in Table 2, show the width of additively manufactured additively manufactured samples in three areas, top, middle, and bottom of additively manufactured additively manufactured samples, respectively. 
Table 2 Input and output parameters of laser AM process

\begin{tabular}{|c|c|c|c|c|c|c|}
\hline \multirow[b]{2}{*}{ No. } & \multicolumn{2}{|c|}{ Inputs } & \multicolumn{4}{|c|}{ Outputs } \\
\hline & $\begin{array}{c}\text { Scanning } \\
\text { speed } \\
(\mathbf{m m} / \mathbf{s})\end{array}$ & $\begin{array}{c}\text { Powder } \\
\text { rate } \\
\text { (gr/min) }\end{array}$ & $\mathbf{W}_{\mathbf{1}}(\boldsymbol{\mu m})$ & $\mathbf{W}_{2}(\mu \mathrm{m})$ & $\mathbf{W}_{\mathbf{3}}(\boldsymbol{\mu m})$ & $h(\mu \mathrm{m})$ \\
\hline$\# 1$ & 5 & 28.52 & 108 & 1280 & 350 & 3105 \\
\hline$\# 2$ & 5 & 17.94 & 862 & 1005 & 594 & 1912 \\
\hline$\# 3$ & 2.5 & 17.94 & 792 & 1253 & 474 & 2767 \\
\hline \#4 & 2.5 & 28.52 & 945 & 1479 & 836 & 4890 \\
\hline
\end{tabular}

Figure 3 and Figure 4 show, respectively, the additively manufactured samples and their geometrical dimensions which are made by the DLMD method. In Figure 3, some parts of additively manufactured additively manufactured are divided for understanding the concept of the height of samples. Also, in Figure 4, the concept of width in their zones for four samples are illustrated.

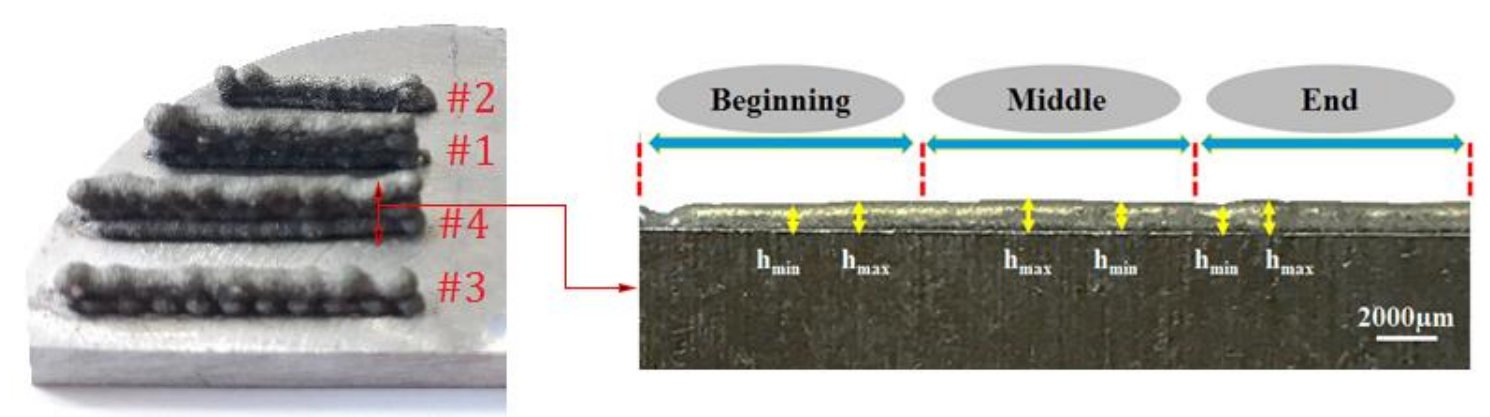

Figure 3. Additively manufactured samples and cross-section of a printed part (thickness of the substrate is $7 \mathrm{~mm}$ )
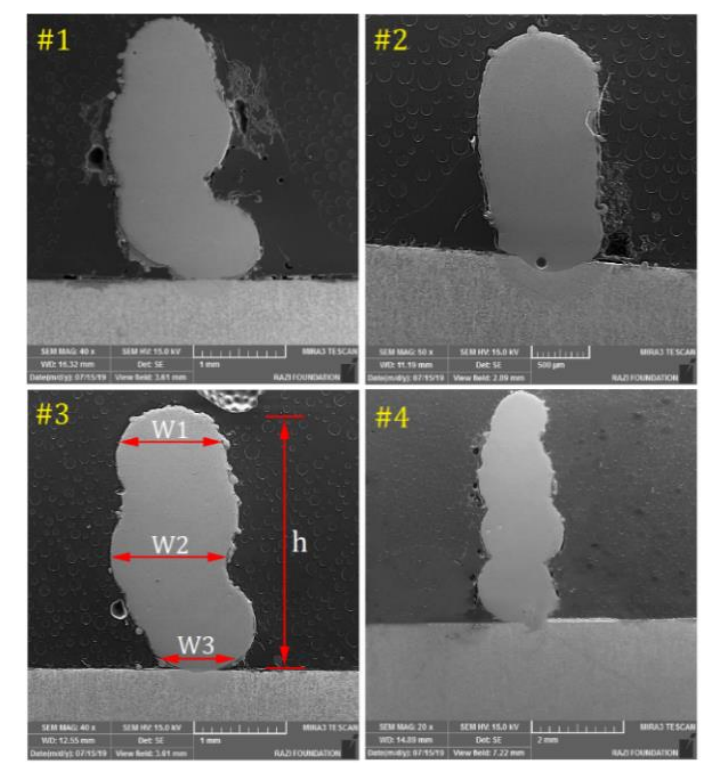

Figure 4. The macro size images of additively manufactured samples 
Measurements of geometric dimensions of the specimens in four parts of deposition sections (beginning (W1), middle (W2), end of the deposition layer (W3), and the height (h)) are determined by the ImageJ software based on FESEM images (see Figure 4). The stability is a modern approach, and it is a suitable criterion for the height quality of deposited layers. The length of the deposited layer is divided into three sections. The maximum and minimum heights are measured, and the differences of the heights are calculated. The maximum difference is defined as stability value. A lower stability rate can be more suitable for this process because the lower amount of stability means that the differences between minimum and maximum heights are less, as is evedient from Figure 3. The equations related to the calaution of stability value are shown in followings:

$$
\begin{aligned}
& \Delta h_{1}=H_{\text {max }_{1}}-H_{\text {min }_{1}} \\
& \Delta h_{2}=H_{\text {max }_{2}}-H_{\text {min }_{2}} \\
& \Delta h_{3}=H_{\text {max }_{3}}-H_{\text {min }_{3}} \\
& \Delta \mathrm{H}=\operatorname{Max}\left\{\Delta h_{1}, \Delta h_{2}, \Delta h_{3}\right\}
\end{aligned}
$$

The microstructure images in this study were captured by using and optical microscope (Device model: RADICAL model RMM- 2) and FE-SEM. ImageJ software was used to analyse the geometric dimensions of the specimens. The Vickers microhardnes for samples were evaluated via BUEHLER models. The specimens were tested with a loading rate of $100 \mathrm{~g}$ for 30 seconds on the microhardness test. Powders feed focus point, spray bandwidth, and powder flow feed rate measurements were examined to characterize the powder feed conditions. To determine the powder focus point, the axial gas feed rate, powder carrier gas feed, and powder feeder rotation speed must be adjusted. This is vital because the powder particles fed from the four outlet channels converge at one particular point. The parameters of scanning speed, distance of laser head to the substrate and the rotation speed of powder feeder were changed to evaluate the effect of parameters. The spray bandwidth is measured by three times along the 
path. The mass feed rate is defined as the feed rate of the powder passing through the powder outlet channels of the twin powder feeder. Powder mass feed rate, gas pressure, and disk powder velocity were varied to measure the mass feed rate. The lens of the fiber laser device has a $\pm 4 \mathrm{~mm}$ displacement, which is related to sample position. The focal point position is at the highest point on -4 mode. Also, at the zero points the focal point is on the substrate [15].

\subsection{Catchment}

The concept of catchment in AM has an applied aspect because it shows the absorption of powder components. According to equation (5), catchment is dependent on the powder feed rate and laser scanning speed. It is expected that the catchment factor increases by increasing the powder feed rate, but the powder feed rate has a turning point. It means that the powder feed rate increases to a certain extent, but suddenly it makes a situation for absorbing more powder, and in this stage, the amount of catchment declines [50].

$$
\text { Catchment }=\frac{\text { Powder flow } \text { rate }(\mathrm{gr})}{\text { Scanning } \text { speed }(\mathrm{mm})}
$$

Generally, the samples' geometry and height are dependent on three input factors; namely, powder feed rate; laser scanning speed; and laser power. The melt pools can absorb more powder by increasing the powder feed rate; however, the height of samples sometimes does not change by increasing the powder feed rate because the laser power is low and the situation for absorbing more powder is not provided in the melted pond. In the specific circumstances, the melt pool, which is created by laser irradiation, can receive and absorb more powder by increasing the powder feed rate. When the powder feed rate and the scanning speed are regulated on a constant amount, generated energy can attend to absorb a limited amount. This phenomenon means that, when the powder feed rate is in the highest rate, it cannot add any more powder to the melt pool. In addition, the uncompleted melting of powder affects samples' height because the input energy 
is low. Also, Cong et al. [51] showed that when the powder feed rate changed from $0.1 \mathrm{gr} / \mathrm{min}$ to $0.4 \mathrm{gr} / \mathrm{min}$, the melt pool caught more powder and finally the height of samples increased. However, the samples' height may still remain constant until the powder feed rate goes to a proper rate. This is because the laser power and scanning speed are regulated on the constant amount and the rate of powder which is absorbed by energy absorption has been limited. The focus on issues of final surface is one of the most critical limitations in the DMD process. The difference between the roughness and waviness as two specific factors in modifications of surface is proposed. Gharbi et al. [52] conducteded a research which showed that tiny additively manufactured layer and bier melt pool improved the quality of surface. Also, it was observed that by increasing the interaction between the powder feed and laser beam, more powder would be absorbed that is one of the most beneficial effects for the final surface. When the amount of catchment is at a high rate, the interaction between powder and laser beam increases, and finally, it makes a surface with improved quality.

\section{Results and Discussion}

\subsection{Effect of catchment parameters on the wall height}

According to Equation (5) the catchment parameter consists of the powder feed rate and scanning speed. The scanning speed is an affecting parameter on the additively manufactured wall geometry. In this research, two different scanning speeds of 2.5 and $5 \mathrm{~mm} / \mathrm{sec}$ were considered. The maximum wall height at the lowest scanning speed $(2.5 \mathrm{~mm} / \mathrm{sec})$ was observed as $4890 \mu \mathrm{m}$. In low scanning speed, the powder particles have more time for deposition. On the other hand, in the high scanning speed, the powder particles have lower absorbed energy, and the additively manufactured wall height will decrease. According to Table 2, the minimum additively manufactured wall height at the highest scanning speed (5 $\mathrm{mm} / \mathrm{s}$ ) was obtained as $1912 \mu \mathrm{m}$. Generally, a reduction in scanning speed causes 
an increase in powder deposition and also wall height. In this study, two powder feed rates of 17.94 and $28.52 \mathrm{~g} / \mathrm{min}$ were used. The maximum additively manufactured wall height was observed at the maximum powder feed rate $(28.52$ $\mathrm{g} / \mathrm{min}$ ). When the powder feed rate increases, much more powder particles interact with the laser beam. The laser beam energy melted and deposited the powder particles on the substrate. The minimum additively manufactured wall height was observed at the minimum powder feed rate $(17.94 \mathrm{~g} / \mathrm{min})$. Figure 5 shows the effects of powder feed rate and scanning speed on the additively manufactured wall height. It is clear that by decreasing the scanning speed when the power rate is considered as a constant parameter, the height of the samples increased. This phenomenon completely depended on the time for the additive process which more powder melted and the hight increased.

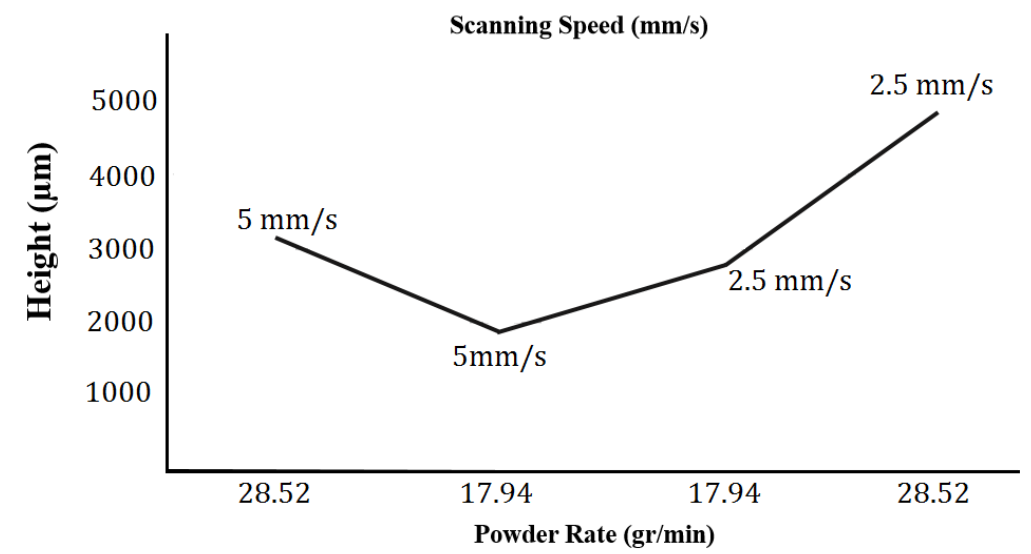

Figure 5. The effect of powder feed rate and scanning speed on wall height.

\subsection{Effect of catchment parameter on the wall width}

The maximum additively manufactured wall width is $1086 \mu \mathrm{m}$, which was observed at minimum scanning speed of $2.5 \mathrm{~mm} / \mathrm{min}$. It was found out that the lower the scanning speed the higher would be the wall width of additively manufactured samples. At a low scanning speed, the powder particles that are interacted and melted by laser beam would have more time to wider deposition, causing an increase in the wall width. The minimum wall width was $820 \mu \mathrm{m}$ that was observed at minimum scanning speed of $2.5 \mathrm{~mm} / \mathrm{min}$. With increasing in the 
powder feed rate, much more powder particles feed coming out from nuzzles and it caused that, more powder interacted with the laser beam and melted. Therefore, the wall width increased. The maximum wall width of additively manufactured samples was observed at powder feed rate of $28.52 \mathrm{~g} / \mathrm{min}$.

\subsection{Elemental and microstructural characterization}

The $\Upsilon$ phase is the base phase in Inconel 718 superalloy called $\Upsilon$ Matrix. In this superalloy, some of other phases such as $\Upsilon^{\prime}, \Upsilon^{\prime \prime}, \delta$, Metallic Carbides (MC) and Laves phases are also generated. The $\Upsilon^{\prime}$ and $\Upsilon^{\prime \prime}$ phases are the main reinforcement phases and those are coherent with $\Upsilon$ phase. The $\Upsilon^{\prime}$ phase composition is $\mathrm{Ni}_{3}\left(\mathrm{Al}-\mathrm{Nb}-\mathrm{Ti}\right.$ ) and the $\mathrm{Y}^{\prime \prime}$ phase composition is $\mathrm{Ni}_{3} \mathrm{Nb}$ [53]. The Laves phases are not desirable in terms of mechanical properties, but the heat treatment can dissolve Laves phases into the matrix. According to Figure 6, the $\Upsilon$ phase is dispersed uniformly in all over the sample microstructure and it is the gray phase. Also, from Figure 6, it is found out that the most part of the additively manufactured sample microstructure is the $\Upsilon$ phase. The white areas in Figure 6a are the Laves phases that are in irregular shapes and dispersed non-uniformly. The Laves phases are precipitated into the grains and in the grain boundaries. The dark-gray areas in Figure 6-b \& c are the $\Upsilon^{\prime}$ phase.
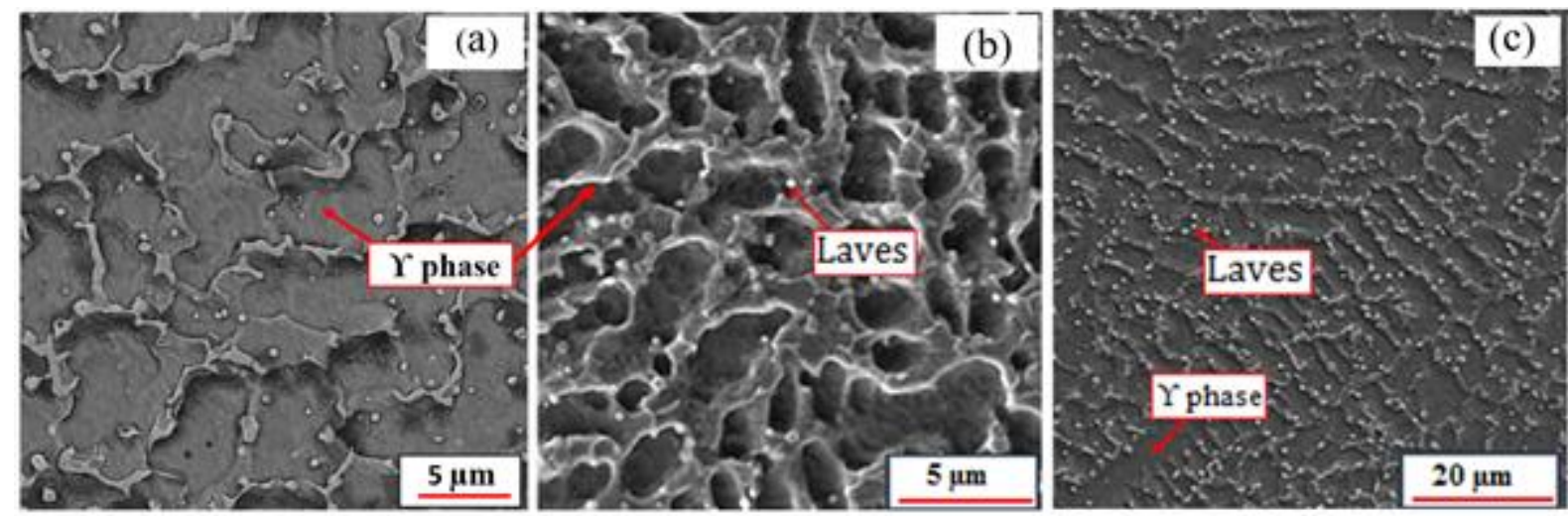

Figure 6. Inconle 718 addetived structure a) $\Upsilon$ phase b) $\Upsilon^{\prime}$ phase c) Laves phases

The EDS analysis provides quantitative and qualitative analyses from a wide range of materials. The microanalysis from different zones of additively 
manufactured samples and substrate was done to achive the point chemical compositions and quantitative and qualitative analyses of phases. The different selected zones from sample \#3 were illustrated in Figure 7.
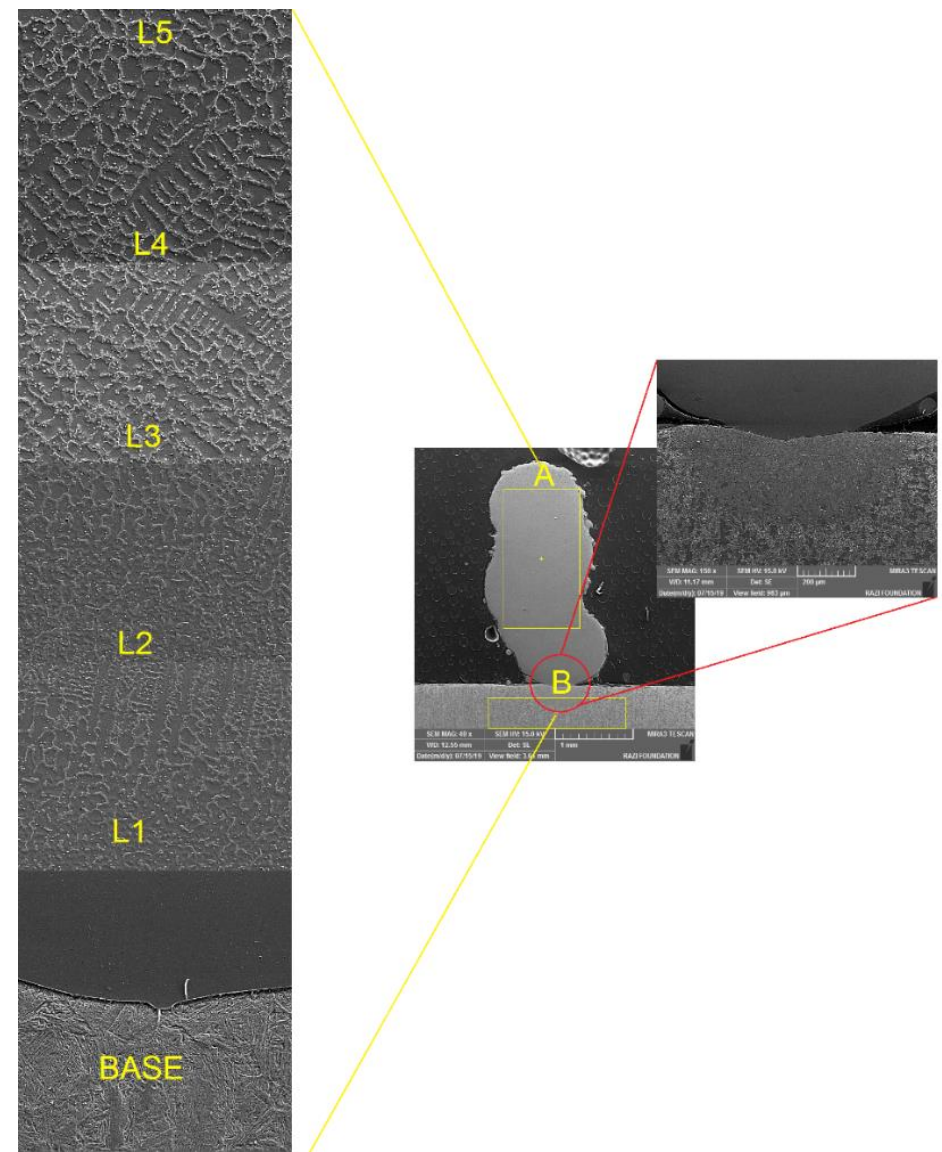

Figure 7. The EDS analysis in 5 layers (L1-L5) of addetived sample \#3

Tables 4 and 5 present the chemical compositions of additively manufactured sample 3 based on atomic and weight percentages in spot A and B, respectively.

Table 4. Chemical composition (Wt. \%) of sample \#3 in spot A 


\begin{tabular}{ccc}
\hline Element & $\begin{array}{c}\text { [norm. } \\
\text { wt\%] }\end{array}$ & [norm. at\%] \\
\hline Aluminium & 0.16 & 0.38 \\
Silicium & 0.91 & 2.12 \\
Titanium & 0.33 & 0.32 \\
Chromium & 16.53 & 20.24 \\
Iron & 14.8 & 17.22 \\
Nickel & 51.75 & 48.50 \\
Niobium & 4.92 & 3.47 \\
Molybdenum & 3.3 & 2.53 \\
Aurum & 7.3 & 5.22 \\
\hline Sum & $\mathbf{1 0 0}$ & $\mathbf{1 0 0}$ \\
\hline
\end{tabular}

Table 5. Chemical composition (Wt. \%) of sample \#3 in spot B

\begin{tabular}{ccc}
\hline Element & [norm. wt\%] & [norm. at\%] \\
\hline Carbon & 6.67 & 25.21 \\
\hline Silicium & 0.36 & 0.58 \\
\hline Chromium & 0.79 & 0.69 \\
\hline Iron & 87.84 & 71.46 \\
\hline Molybdenum & 4.34 & 2.06 \\
\hline Sum & 100 & 100 \\
\hline
\end{tabular}

The Map analysis provides the frequent distribution of elements in an image. In any area where the color intensity is higher, it indicates that the percentage of the element in that area is higher. Figure 8 shows the Map analysis of sample number 4 . The elements distribution in the Inconel 718 additively manufactured samples were illustrated in different colors. According to ICP analysis, the most parts of the elemental composition of Inconel 718 powder included the $\mathrm{Ni}, \mathrm{Cr}$, $\mathrm{Fe}, \mathrm{Nb}$, and Mo elements. The main elements of powder particles were $\mathrm{Ni}, \mathrm{Cr}$, and Fe by the weight percentages of 54\%, 19\% and $17.5 \%$, respectively. The Map images showed the uniform distribution of $\mathrm{Ni}, \mathrm{Co}, \mathrm{Cr}$, and $\mathrm{Ti}$ elements all over the sample. The brighter spots in the Map images indicate the more intensity of elements distribution. The $\mathrm{Al}, \mathrm{Nb}, \mathrm{Mo}$, and $\mathrm{Si}$ elements are distributed nonuniformly and accumulated in grains boundaries. The Laves phases will be precipitated in the grain boundaries. The atomic percentage of $\mathrm{Nb}$ and $\mathrm{Mo}$ elements are higher in the Laves phases than the other phases, thus the $\mathrm{Nb}$ and Mo elements were accumulated in grains boundaries. During the DLMD process, the powders melted. The elements are uniformly distributed in the molten 
materials, but during the solidification process, the alloying elements will be accumulated in the grain boundaries. In the Inconel 718 alloy, both the $\mathrm{Nb}$ and Mo elements are susceptible to separation due to the small redistribution coefficient $(<1)$, which causes a non-uniformity distribution of the alloy composition in the solid-liquid interface.

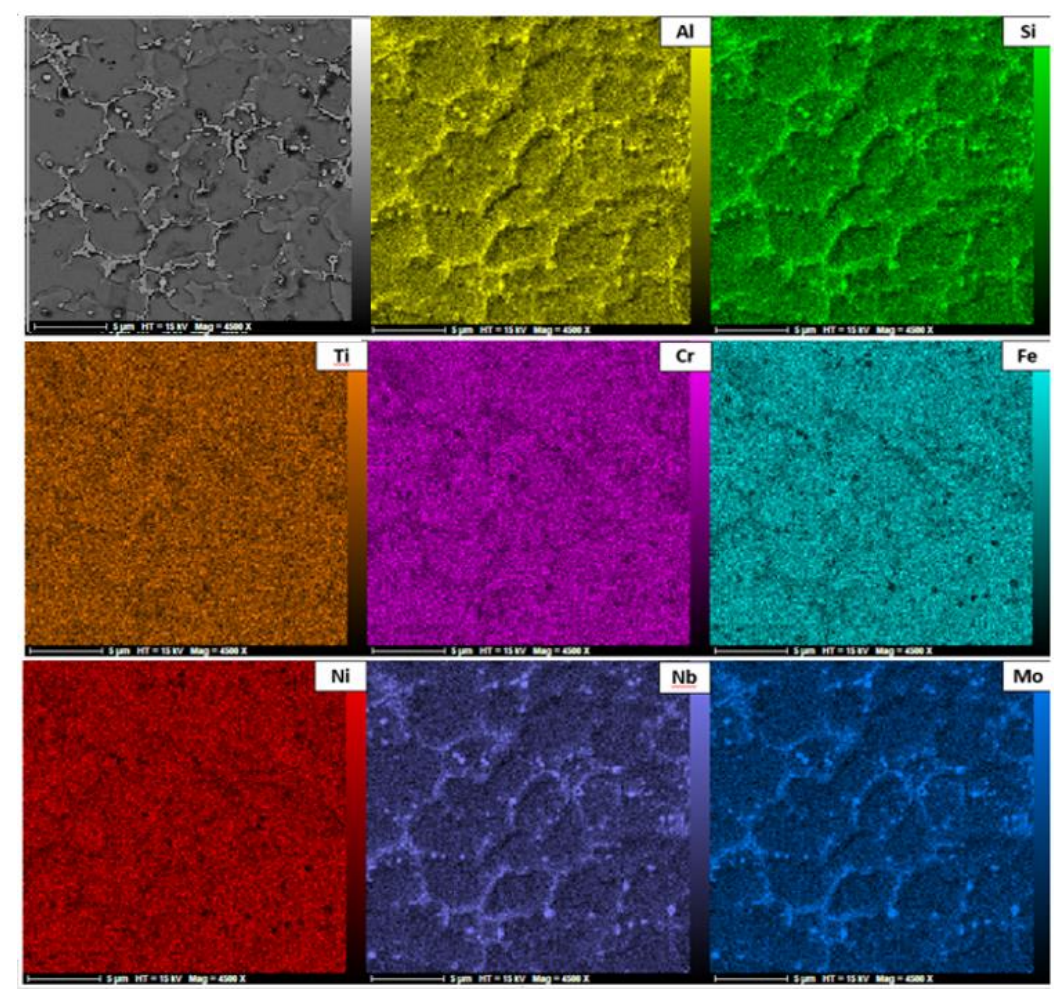

Figure 8. Map analysis of sample number 4.

The grain morphology of Inconel 718 is diverse in different regions. Columnar dendrites, cellular dendrites, cells, and equiaxial dendrites with Laves phases are observed in the interdendritic areas. Generally, the grain growth was epitaxial, but in some areas, the dendritic growth was observed. The dendrites were grown along of the deposition layer direction. The Microstructure of Inconel 718 is columnar dendrites growing epitaxially along the deposition direction. Figure 9 shows the FE-SEM images for samples number 1 to 4 . The columnar growth was observed, and in some areas, the grains were more extensive and more stretched. 

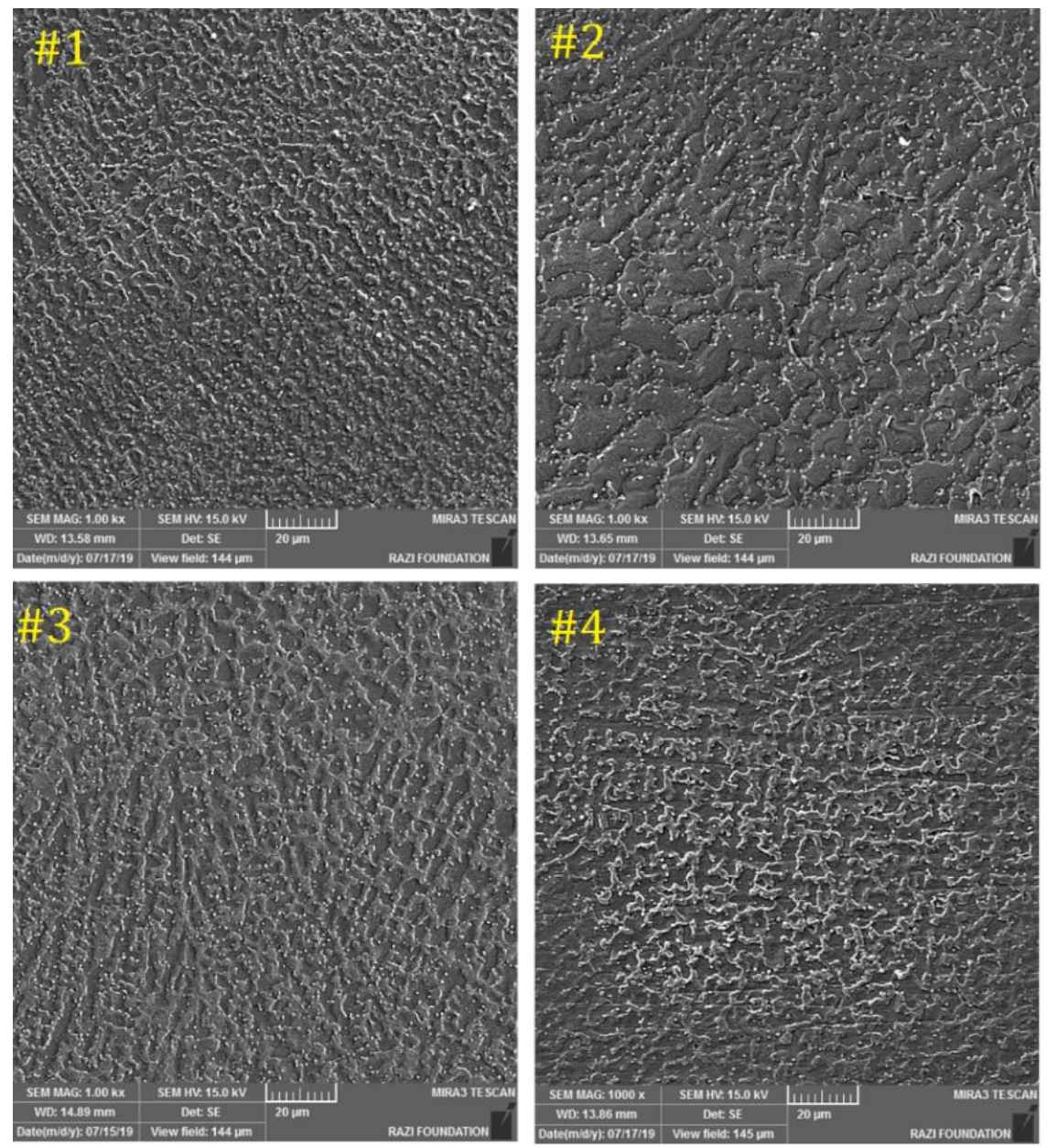

Figure 9. FE-SEM of samples number 1 to 4.

The orientation of grains changed in the areas near to the substrate. The substrate acts as a heat source for the first layers of deposited wall, and large columnar dendrites were grown. When laser energy melted the new layer, it simultaneously affected an earlier layer and caused grain growth in previous layer. The grain growth would occur due to increase in temperature and reheating the layer. Figure 10 showed the growth in grain size in the overlap zone of two layers. 


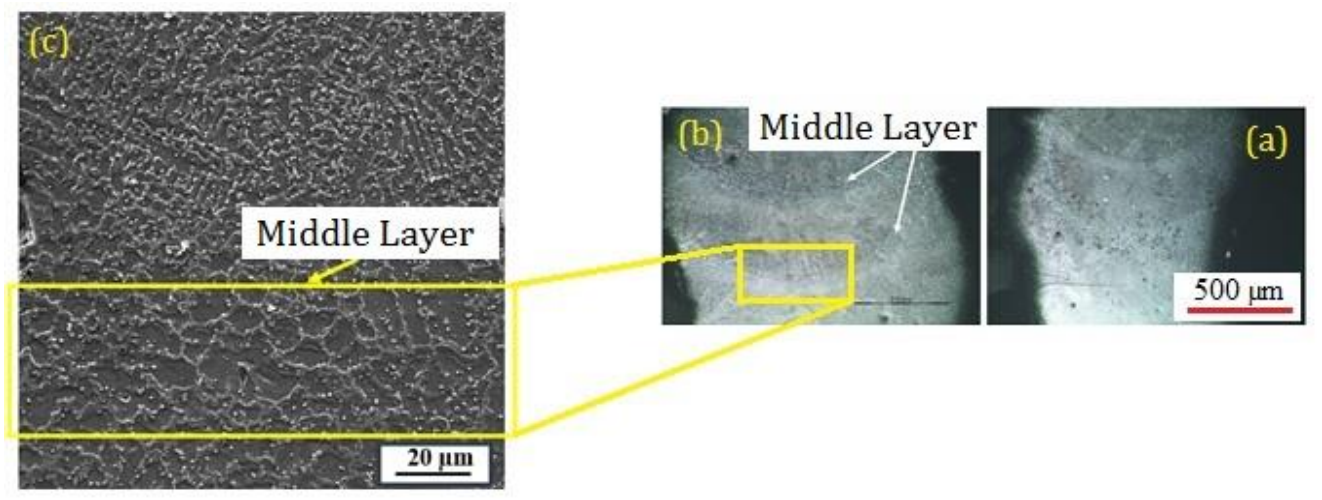

Figure 10. The common boundary between the deposit layers.

The heat input of the laser beam from the upper layer is affected by the interfaces of layers, and the grains are grown. Figure 11 shows the microstructure of samples number 1 and 4 . The laser power was $250 \mathrm{~W}$. Thus, the heat input changed due to the alteration of scanning speeds. When adding melted upper layer to the hardened layer or lower layer, the solidified layer was affected by heat input caused from the upper layer. Therefore, grains of lower layers were grown. A high laser power leads to a deeper melt pool, whereas a low scanning speed causes much more powder particles to be deposited in the melt pool. Therefore, at low scanning speed, strong joints between layers are created, and it will avoid cracking and separating in the interfaces.
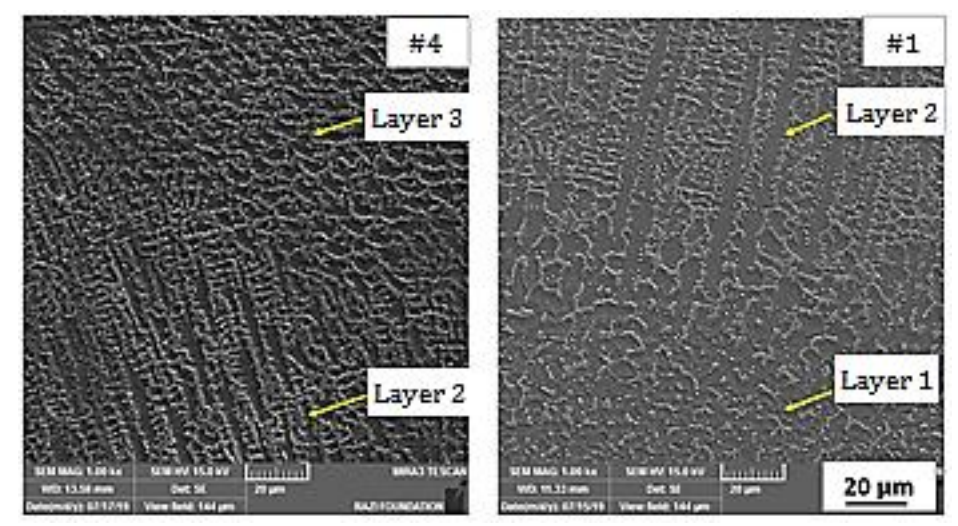

Figure 11. The common boundary layer of samples number 1 and 4 .

In Figure 12, the equiaxed dendritic microstructures at the surface of deposition were illustrated. With increasing in the additively manufactured wall height, the grains orientation in top section of samples is differed from the parts, 
which are near to the substrate. The columnar microstructure with equiaxed dendrites showed that changes in the microstructure is caused by the changing solidification conditions at top of the deposition. In the top sections of samples, the columnar grains and equiaxed dendrites were created due to low-temperature gradients and high solidification speed [54-56].

The top of the workpiece after the deposition of the melted substrate could be quenched by air; however, the bottom of the melted substrate is quenched by thermal transformation to the lower layer, which is addetived before. Furthermore, in the top sections of additively manufactured samples, the molten powder particles interacted with the Ar shielding gas. Thus, the solidification velocity increased. The convection heat transfer between the last solidified layer and shielding gas was occurred in top layers of additively manufactured samples, while in the lower layers, the conduction heat transfer between additively manufactured layers and previous layers have occurred.
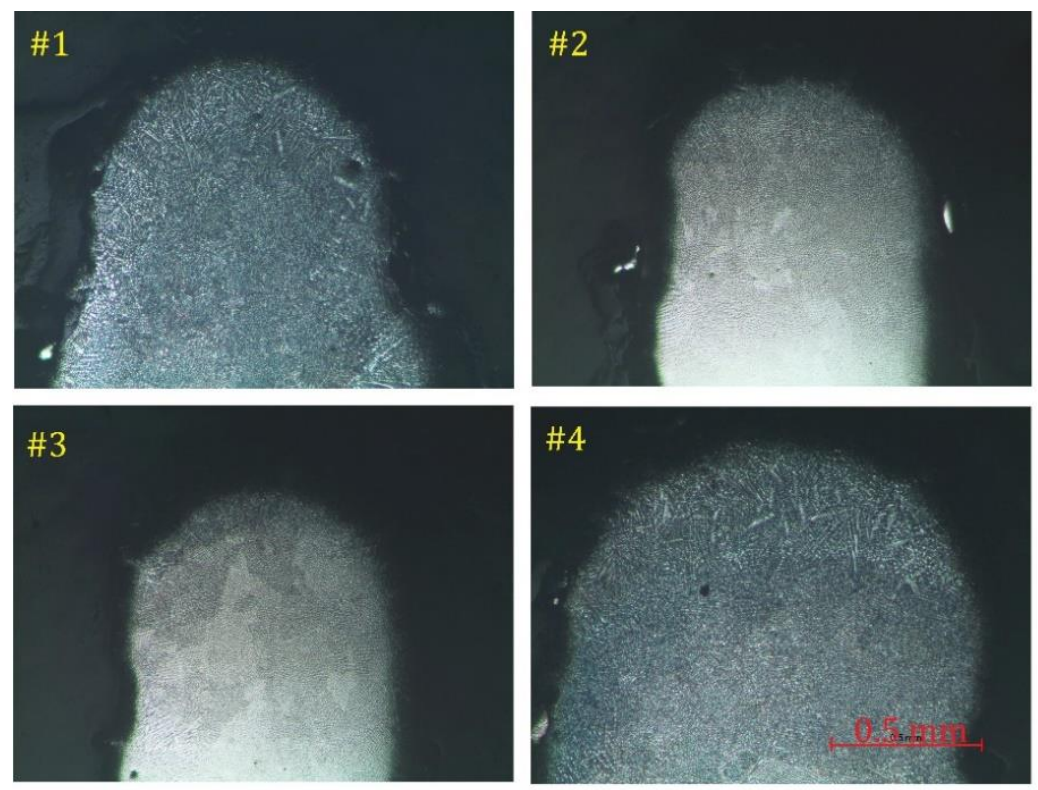

Figure 12. Top section microstructure of the additively manufactured samples for samples \#1 to \#4

The additively manufactured samples may have some defects, such as porosity, open pores, and shirinkage cavities. The porosity and unmelted powders are the usual defects that may happen during the AM process. In Figure 13, it is shown that the closed and open pores are the black spots. The porosity of the 
additively manufactured samples is due to the powder quality and excessive pressure of shielding gas flow [57]. The powder particles quality depends on powder production methods. The powders produced by PREP and GA methods are better powders than the other powder production methods for reducing the porosity in the additively manufactured samples. In this research, Inconel 718 powder particles were gas atomized and made lower porosity in the additively manufactured samples.
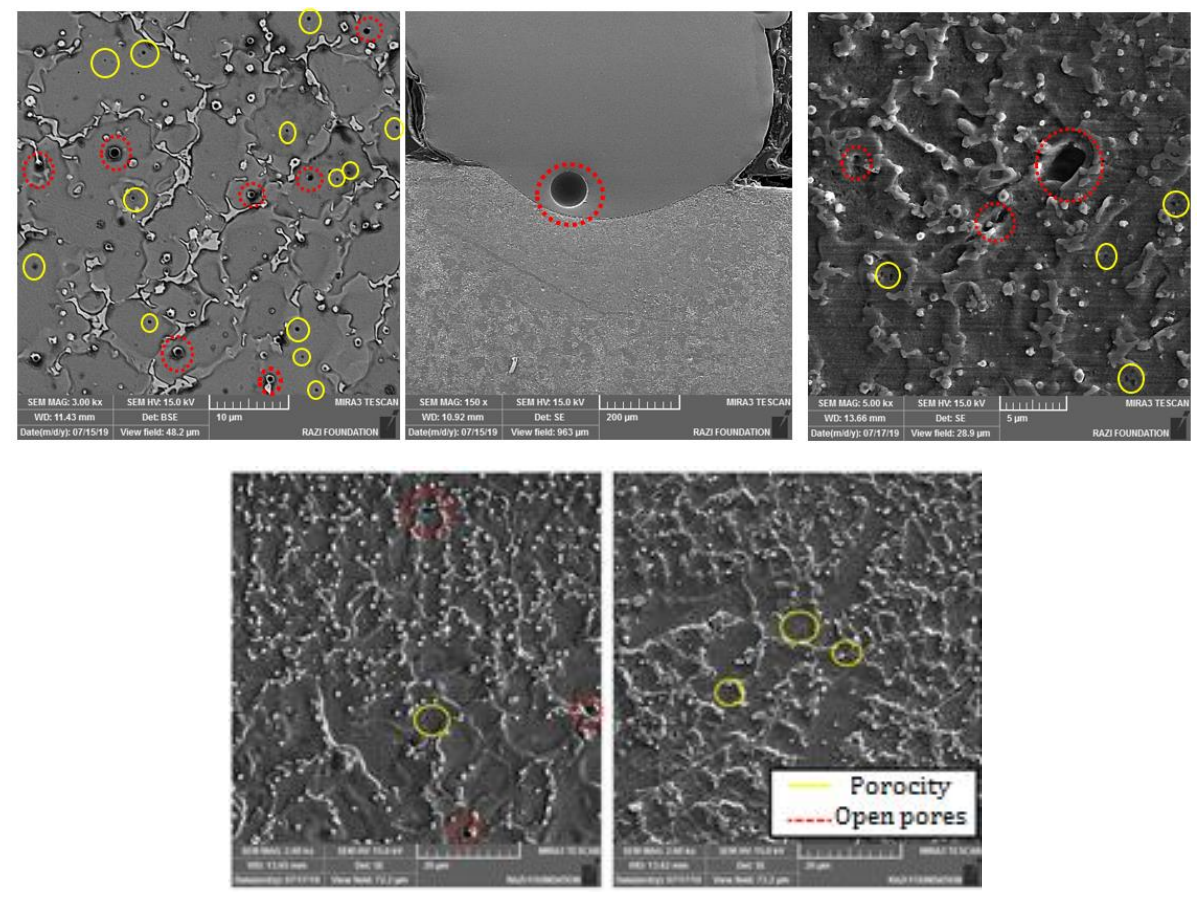

Figure 13. Defects in the microstructure of the addetived samples

\subsection{Microhardness characteristics}

The values of Vickers microhardness of Sample No. 1 and Sample No. 4 from top to bottom are illustrated in Figure 14. The microhardness values of the additively manufactured samples following a fluctuated trend. Based on the nonuniform cooling rate and non-steady solidification rates of molten Inconel 718 during the AM process. It is due to the heat input from upper layers that affected the lower layer, and changed the microstructure, grain size as well as microhardness. In other words, the heat input from the upper additively manufactured layer led to an increase in microhardness of lower additively 
manufactured layers. It is worth mentioning that the morphology and concentration of the Laves phase were found to be the most critical factors in the microstructure of Inconel 718 alloy. On the other hand, as mentioned in section 3.2, the Laves phase is not a hard phase. The Laves phase is the Nb-rich phase in the $\Upsilon$ matrix (see Figure 6 and Figure 8). Accordingly, the precipitation of the Laves phase reduced the microhardness of the additively manufactured samples.
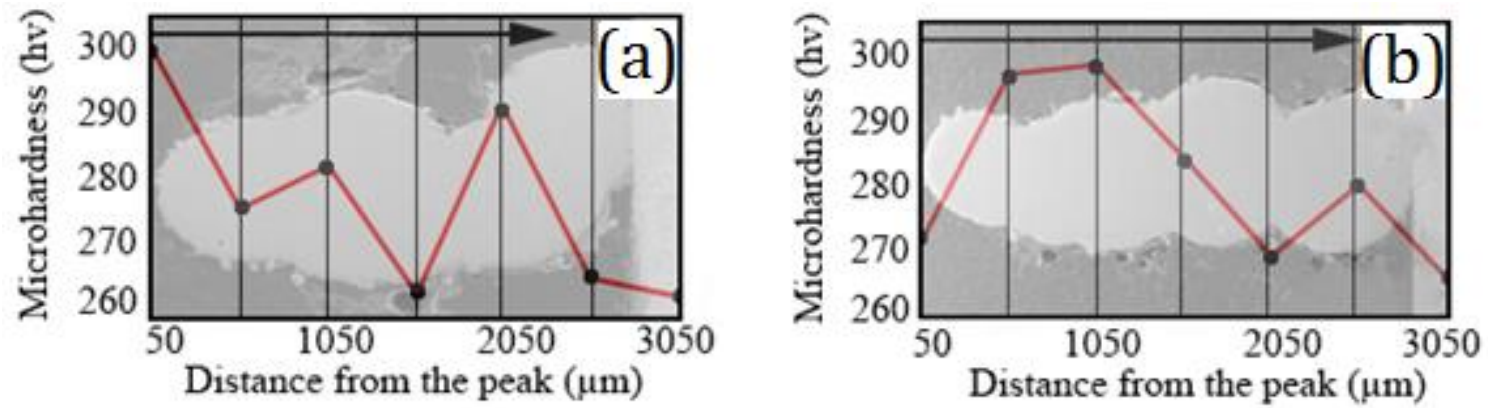

Figure 14. Microhardness of samples a) number 1 and b) number 4 .

\section{Conclusions}

In this study, the influence of two effective parameters on the direct laser metal deposition (DLMD) of additive manufacturing (AM) process for Inconel 718 superalloy was examined. The results showed that the powder feed rate and scanning speed have an effectual impact on the additively manufactured samples features. The following conclusions are made:

1. The height of the samples depends on two main factors, namely, scanning speed and powder feed rate. When the scanning speed decreases, the laser's interaction time with the powder particles increases, which leads to a higher additively manufactured wall height.

2. The average width of the deposited layer depends on the scanning speed and the powder feed rate. By declining the scanning speed to $2.5 \mathrm{~mm} / \mathrm{s}$, the deposition from the melted powder having more time for going wider width and is developed to $1479 \mu \mathrm{m}$ on bottom of workpieces. 
3. Height stability is an important parameter in measuring the quality of the additively manufactured samples. A low $\Delta \mathrm{H}$ value means that the difference between the highest and the lowest heights of the sample is lower. The lowest $\Delta \mathrm{H}$, which has proper stability, is obtained in the less scanning speed.

4. Change of microhardness in the samples does not follow any specific trend. The microstructural changes along with the height of a sample by DLMD. The heat input from the upper layers that affected the lower layer and the laser heat input acts as a heat treatment.

5. Various phases with different grain growth morphology in different parts of additively manufactured samples are generated which cause fluctuiation in microhardness regims.

6. In DLMD of Inconel 718 superalloy, during the solidification process, the alloying elements such as: $\mathrm{Nb}$ and $\mathrm{Mo}$, will be accumulated in the grain boundaries. The Laves phases are $\mathrm{Nb}$ and Mo rich phases, thus the Laves phases will be precipitated in the grain boundaries. The Laves phases are not desirable in terms of echanical properties.

\section{Declaration of competing interest}

\section{Conflict of Interest}

Potential conflict of interest exists:

We wish to draw the attention of the Editor to the following facts, which may be considered as potential conflicts of interest, and to significant financial contributions to this work:

The nature of potential conflict of interest is described below:

$\bigotimes$ No conflict of interest exists.

We wish to confirm that there are no known conflicts of interest associated with this publication and there has been no significant financial support for this work that could have influenced its outcome.

\section{Funding}

$\square$ Funding was received for this work. 
All of the sources of funding for the work described in this publication are acknowledged below:

$\bigotimes$ No funding was received for this work.

\section{Intellectual Property}

$\bigotimes W e$ confirm that we have given due consideration to the protection of intellectual property associated with this work and that there are no impediments to publication, including the timing of publication, with respect to intellectual property. In so doing we confirm that we have followed the regulations of our institutions concerning intellectual property.

\section{Research Ethics}

$\bigotimes W e$ further confirm that any aspect of the work covered in this manuscript that has involved human patients has been conducted with the ethical approval of all relevant bodies and that such approvals are acknowledged within the manuscript.

ХIRB approval was obtained (required for studies and series of 3 or more cases)

\Written consent to publish potentially identifying information, such as details or the case and photographs, was obtained from the patient(s) or their legal guardian(s).

\section{$\underline{\text { 5. Authorship }}$}

The International Committee of Medical Journal Editors (ICMJE) recommends that authorship be based on the following four criteria:

1. Substantial contributions to the conception or design of the work; or the acquisition, analysis, or interpretation of data for the work; AND

2. Drafting the work or revising it critically for important intellectual content; AND

3. Final approval of the version to be published; AND

4. Agreement to be accountable for all aspects of the work in ensuring that questions related to the accuracy or integrity of any part of the work are appropriately investigated and resolved.

All those designated as authors should meet all four criteria for authorship, and all who meet the four criteria should be identified as authors. For more information on authorship, please see http://www.icmje.org/recommendations/browse/roles-and-responsibilities/defining-the-role-ofauthors-and-contributors.html\#two.

\All listed authors meet the ICMJE criteria. creation of this manuscript, each having fulfilled criteria as established by the ICMJE.

$\square$ One or more listed authors do(es) not meet the ICMJE criteria.

We believe these individuals should be listed as authors because:

$\bigotimes \mathrm{We}$ confirm that the manuscript has been read and approved by all named authors.

$W$ e confirm that the order of authors listed in the manuscript has been approved by all named authors. 


\section{Contact with the Editorial Office}

The Corresponding Author declared on the title page of the manuscript is:

\This author submitted this manuscript using his/her account in EVISE.

$\triangle W e$ understand that this Corresponding Author is the sole contact for the Editorial process (including EVISE and direct communications with the office). He/she is responsible for communicating with the other authors about progress, submissions of revisions and final approval of proofs.

\We confirm that the email address shown below is accessible by the Corresponding Author, is the address to which Corresponding Author's EVISE account is linked, and has been configured to accept email from the editorial office of American Journal of Ophthalmology Case Reports:

Mahmoud Moradi ad6683@coventry.ac.uk

Zeynab Pourmand zeinabpourmand2646@gmail.com

Arman Hasani arman_hasani_2010@yahoo.com

Mojtaba Karami Moghadam mojtaba.kmoghadam1991@gmail.com

Amir Hosein Sakhaei a.sakhaei@kent.ac.uk

Mahmood Shafiee m.shafiee@kent.ac.uk

Jonathan Lawrence ac5588@,coventry.ac.uk

$\square$ Someone other than the Corresponding Author declared above submitted this manuscript from his/her account in EVISE:

\We understand that this author is the sole contact for the Editorial process (including EVISE and direct communications with the office). He/she is responsible for communicating with the other authors, including the Corresponding Author, about progress, submissions of revisions and final approval of proofs.

We the undersigned agree with all of the above.

Author's name (Fist, Last)

1. Mahmoud Moradi

2. Zeynab Pourmand
Signature

Date

Mahmoud Moradi

$23 / 04 / 2021$

Zeynab Pourmand

$23 / 04 / 2021$ 
3. Arman Hasani Arman Hasani 23/04/2021

4. Mojtaba Karami Moghadam Mojtaba Karami Moghadam 23/04/2021

5. Amir Hosein Sakhaei Amir Hosein Sakhaei 23/04/2021

6. Mahmood Shafiee Mahmood Shafiee 23/04/2021

7. Jonathan Lawrence Jonathan Lawrence 23/04/2021

\section{References}

[1]. T. D. Ngoa, A. Kashania, G. Imbalzanoa, K. T.Q. Nguyena, D. Huib, (2018). Additive manufacturing (3D printing): A review of materials, methods, applications and challenges. Composites Part B (143), 172-196.

[2]. J. C. Najmon, S. Raeisi, A. Tovar, (2019). Review of additive manufacturing technologies and applications in the aerospace industry, Additive Manufacturing for the Aerospace Industry, 7-31.

[3]. H. Bikas, P. Stavropoulos, G. Chryssolouris, (2016). Additive manufacturing methods and modeling approaches: a critical review. Advanced Manufacturing Technology, 83(1-4), 389405.

[4]. D. Clark, M. T.Whittaker, M. R.Bache, (2012). Microstructural characterization of a prototype titanium alloy structure processed via direct laser deposition (DLD). Metallurgical and Materials Transactions B, 43(2), 388-396.

[5]. M. Moradi, S. Meiabadi, A. Kaplan, (2019). 3D Printed Parts with Honeycomb Internal Pattern by Fused Deposition Modelling; Experimental Characterization and Production Optimization. Metals and Materials International, 25 (5), 1312-1325.

[6]. Y. Yang, Dongdong Gu, D. Dai, C. Ma, (2018). Laser energy absorption behavior of powder particles using ray tracing method during selective laser melting additive manufacturing of aluminum alloy, Materials \& Design, 143, 12-19.

[7]. I. F. Ituartea, N. Boddetib, V. Hassanib, M. L. Dunnb, D. W. Rosenb, (2019), Design and additive manufacture of functionally graded structures based on digital materials, Additive Manufacturing, 30, 100839.

[8] Moradi, M., Karami Moghadam, M. and Asgari, F., (2020). 4D printing additive manufacturing review; Mechanisim, Chalanges, Applications and Future, Modares Mechanical Engineering, 20(4), 1063-1077.

[9]. S. M. Thompson, L. Bian, N. Shamsaei, A. Yadollahi, (2015). An Overview of Direct Laser Deposition for Additive Manufacturing Part I: Transport Phenomena, Modeling and Diagnostics, Additive Manufacturing, 8, 36-62.

[10] Moradi, M., Karami Moghadam, M., Shamsborhan, M. and Bodaghi, M., 2020. The Synergic Effects of FDM 3D Printing Parameters on Mechanical Behaviors of Bronze Poly Lactic Acid Composites. Journal of Composites Science, 4(1), 17.

[11]. N. Shamsaeia, A. Yadollahia, L. Bianc, S. M. Thompsona, (2015). An overview of Direct Laser Deposition for additive manufacturing; Part II: Mechanical behavior, process parameter optimization and control, Additive Manufacturing, 8, 12-35. 
[12]. T.E. Abioye, P. K. Farayibi, A.T. Clare, (2017). A Comparative Study of Inconel 625 Laser Cladding by Wire and Powder Feedstock, Materials and Manufacturing Processes, 32(14), 1653-1659.

[13]. T.E. Abioye, D.G. McCartney, A.T. Clarea, (2017). Laser cladding of Inconel 625 wire for corrosion protection, Materials Processing Technology, 217, 232-240.

[14]. T. E. Abioye, A. Medrano-Tellez, P. K. Farayibi, P. K. Oke, (2017). Laser Metal Deposition of Multi-Track Walls of 308LSi Stainless Steel, Materials and Manufacturing Processes, 32(14), 1660-1666.

[15] Moradi, M., Ashoori, A., \& Hasani, A. (2020). Additive manufacturing of stellite 6 superalloy by direct laser metal deposition-Part 1: Effects of laser power and focal plane position. Optics \& Laser Technology, 106328.

[16] Moradi, M.; Karami Moghadam, M.; Shamsborhan, M.; Bodaghi, M.; Falavandi, H., (2020). Post-Processing of FDM 3D-Printed Polylactic Acid Parts by Laser Beam Cutting. Polymers, 12, 550.

[17] Moradi, M., Falavandi, H., Karami Moghadam, M., Meiabadi, S.M. and Saleh, M., (2020). Experimental Investigation on Laser Cutting Post Process of Additive Manufactured Parts of Poly Lactic Acid (PLA) by 3D Printers Using FDM Method. Modares Mechanical Engineering, 20(4), 999-1009.

[18] Li, W., Yan, L., Karnati, S., Liou, F., Newkirk, J., Taminger, K. M. B., \& Seufzer, W. J. (2017). Ti-Fe intermetallics analysis and control in joining titanium alloy and stainless steel by Laser Metal Deposition. Journal of Materials Processing Technology, 242, 39-48.

[19] Angelastro, A., Campanelli, S. L., \& Casalino, G. (2017). Statistical analysis and optimization of direct metal laser deposition of 227-F Colmonoy nickel alloy. Optics \& Laser Technology, 94, 138-145.

[20] Caiazzo, F., Alfieri, V., Argenio, P., \& Sergi, V. (2017). Additive manufacturing by means of laser-aided directed metal deposition of 2024 aluminium powder: investigation and optimization. Advances in Mechanical Engineering, 9(8), 1687814017714982.

[21] Savitha, U., Srinivas, V., Reddy, G. J., Gokhale, A. A., \& Sundararaman, M. (2018). Additive laser deposition of YSZ on Ni base superalloy for thermal barrier application. Surface and Coatings Technology, 354, 257-267.

[22] Donadello, S., Motta, M., Demir, A. G., \& Previtali, B. (2019). Monitoring of laser metal deposition height by means of coaxial laser triangulation. Optics and Lasers in Engineering, $112,136-144$.

[23] Liu, W., \& DuPont, J. N. (2003). Fabrication of functionally graded TiC/Ti composites by laser engineered net shaping. Scripta materialia, 48(9), 1337-1342.

[24] Sahasrabudhe, H., Harrison, R., Carpenter, C., \& Bandyopadhyay, A. (2015). Stainless steel to titanium bimetallic structure using LENS ${ }^{\mathrm{TM}}$. Additive Manufacturing, 5, 1-8.

[25] Lima, D. D., Mantri, S. A., Mikler, C. V., Contieri, R., Yannetta, C. J., Campo, K. N., \& Banerjee, R. (2017). Laser additive processing of a functionally graded internal fracture fixation plate. Materials \& Design, 130, 8-15

[26] Heer, B., \& Bandyopadhyay, A. (2018). Compositionally graded magnetic-nonmagnetic bimetallic structure using laser engineered net shaping. Materials Letters, 216, 16-19.

[27] Zhang, Y., \& Bandyopadhyay, A. (2018). Direct fabrication of compositionally graded Ti-Al2O3 multi-material structures using Laser Engineered Net Shaping. Additive Manufacturing, 21, 104-111.

[28] Morrow, B. M., Lienert, T. J., Knapp, C. M., Sutton, J. O., Brand, M. J., Pacheco, R. M., \& Gray, G. T. (2018). Impact of defects in powder feedstock materials on microstructure of 304L and 316L stainless steel produced by additive manufacturing. Metallurgical and 
Materials Transactions A, 49(8), 3637-3650.

[29] Prashanth, K. G., Shahabi, H. S., Attar, H., Srivastava, V. C., Ellendt, N., Uhlenwinkel, V., \& Scudino, S. (2015). Production of high strength Al85Nd8Ni5Co2 alloy by selective laser melting. Additive Manufacturing, 6, 1-5.

[30] Matilainen, V. P., Piili, H., Salminen, A., \& Nyrhilä, O. (2015). Preliminary investigation of keyhole phenomena during single layer fabrication in laser additive manufacturing of stainless steel. Physics Procedia, 78, 377-387.

[31] Kong, D., Dong, C., Ni, X., Zhang, L., Man, C., Zhu, G., \& Li, X. (2019). Effect of TiC content on the mechanical and corrosion properties of Inconel 718 alloy fabricated by a highthroughput dual-feed laser metal deposition system. Journal of Alloys and Compounds, 803, 637-648.

[32] Wolff, S. J., Gan, Z., Lin, S., Bennett, J. L., Yan, W., Hyatt, G., \& Cao, J. (2019). Experimentally validated predictions of thermal history and microhardness in laser-deposited Inconel 718 on carbon steel. Additive Manufacturing, 27, 540-551.

[33] Lee, Y. S., \& Farson, D. F. (2016). Surface tension-powered build dimension control in laser additive manufacturing process. The International Journal of Advanced Manufacturing Technology, 85(5-8), 1035-1044.

[34] Shamsaei, N., Yadollahi, A., Bian, L., \& Thompson, S. M. (2015). An overview of Direct Laser Deposition for additive manufacturing; Part II: Mechanical behavior, process parameter optimization and control. Additive Manufacturing, 8, 12-35.

[35] Zhong, C., Kittel, J., Gasser, A., \& Schleifenbaum, J. H. (2019). Study of nickel-based super-alloys Inconel 718 and Inconel 625 in high-deposition-rate laser metal deposition. Optics \& Laser Technology, 109, 352-360.

[36] Petrat, T., Brunner-Schwer, C., Graf, B., \& Rethmeier, M. (2019). Microstructure of Inconel 718 parts with constant mass energy input manufactured with direct energy deposition. Procedia Manufacturing, 36, 256-266.

[37] Li, S., Xiao, H., Liu, K., Xiao, W., Li, Y., Han, X., \& Song, L., (2017). Melt-pool motion, temperature variation and dendritic morphology of Inconel 718 during pulsed-and continuouswave laser additive manufacturing: A comparative study. Materials \& Design, 119, 351-360.

[38] Liu, Z., Kim, H., Liu, W., Cong, W., Jiang, Q., \& Zhang, H. (2019). Influence of energy density on macro/micro structures and mechanical properties of as-deposited Inconel 718 parts fabricated by laser engineered net shaping. Journal of Manufacturing Processes, 42, 96-105.

[39] Liu, Z., Li, T., Ning, F., Cong, W., Kim, H., Jiang, Q., \& Zhang, H. (2019). Effects of deposition variables on molten pool temperature during laser engineered net shaping of Inconel 718 superalloy. The International Journal of Advanced Manufacturing Technology, 102(1-4), 969-976.

[40] Shang, C., Xu, G., Wang, C., Yang, G., \& You, J. (2019). Laser deposition manufacturing of bimetallic structure from TA15 to inconel 718 via copper interlayer. Materials Letters, 252, 342-344.

[41] Caiazzo, F. (2018). Laser-aided Directed Metal Deposition of Ni-based superalloy powder. Optics \& Laser Technology, 103, 193-198.

[42] Liu, Y., Liu, C., Liu, W., Ma, Y., Tang, S., Liang, C., \& Zhang, C. (2019). Optimization of parameters in laser powder deposition AlSi10Mg alloy using Taguchi method. Optics \& Laser Technology, 111, 470-480.

[43] Wang, T., Zhu, Y. Y., Zhang, S. Q., Tang, H. B., \& Wang, H. M. (2015). Grain morphology evolution behavior of titanium alloy components during laser melting deposition additive manufacturing. Journal of Alloys and Compounds, 632, 505-513.

[44] Bhardwaj, T., Shukla, M., Paul, C. P., \& Bindra, K. S. (2019). Direct energy deposition- 
laser additive manufacturing of titanium-molybdenum alloy: Parametric studies, microstructure and mechanical properties. Journal of Alloys and Compounds, 787, 1238-1248. [45] N. Momenzadeh, N., Rahmati, S., Azari, A. (2015). Design, Simulation and Analysis of a novel customized dental implant using Additive Manufacturing Technology, I. J. of Manufacturing Engineering, 2, 52-58.

[46] Reichardt, 44A., Dillon, R. P., Borgonia, J. P., Shapiro, A. A., McEnerney, B. W., Momose, T., \& Hosemann, P., (2016). Development and characterization of Ti-6Al-4V to 304L stainless steel gradient components fabricated with laser deposition additive manufacturing. Materials \& Design, 104, 404-413.

[47] Guo, P., Zou, B., Huang, C., Gao, H. (2017). Study on microstructure, mechanical properties and machinability of efficiently additive manufactured AISI 316L stainless steel by high-power direct laser deposition. Journal of Materials Processing Technology, 240, 12-22.

[48] Pinkerton, A. J. (2015). Advances in the modeling of laser direct metal deposition. Journal of laser applications, 27(S1), S15001.

[49] George F. Vander Voort, ASM Handbook Volume 9: Metallography and Microstructures, The materials information company, 1992.

[50] Moradi, M., Hasani, A., Beiranvand, Z.M. and Ashoori, A., (2020). Additive manufacturing of stellite 6 superalloy by direct laser metal deposition-Part 2: Effects of scanning pattern and laser power reduction in differrent layers. Optics \& Laser Technology, 106455 .

[51] Hu, Y., Wang, H., Ning, F., \& Cong, W., (2016). Laser engineered net shaping of commercially pure titanium: effects of fabricating variables. In International Manufacturing Science and Engineering Conference, American Society of Mechanical Engineers, 49897, V001T02A035.

[52] Gharbi, M., Peyre, P., Gorny, C., Carin, M., Morville, S., Le Masson, P. \& Fabbro, R. (2013). Influence of various process conditions on surface finishes induced by the direct metal deposition laser technique on a $\mathrm{Ti}-6 \mathrm{Al}-4 \mathrm{~V}$ alloy. Journal of materials processing technology, 213(5), 791-800.

[53] Liu, F., Lin, X., Yang, G., Song, M., Chen, J., \& Huang, W. (2011). Microstructure and residual stress of laser rapid formed Inconel 718 nickel-base superalloy. Optics \& laser technology, 43(1), 208-213.

[54] Baeslack, W. A., and Nelson, D. E. (1986). Morphology of weld heat-affected zone liquation in cast alloy 718, Metallography, 19(3), 371-379.

[55] Gäumann, M., Henry, S., Cleton, F., Wagniere, J. D., \& Kurz, W. (1999). Epitaxial laser metal forming: analysis of microstructure formation. Materials Science and Engineering: A, 271(1-2), 232-241.

[56] S. Sui, J. Chen, Z. Li, H. Li, X. Zhao, and H. Tan, (2020). Investigation of dissolution behavior of laves phase in inconel 718 fabricated by laser directed energy deposition, Addit. Manuf., 32, 101055.

[57] Gäumann, M., Bezencon, C., Canalis, P., \& Kurz, W. (2001). Single-crystal laser deposition of superalloys: processing-microstructure maps. Acta materialia, 49(6), 1051-1062. 


\section{Figures}
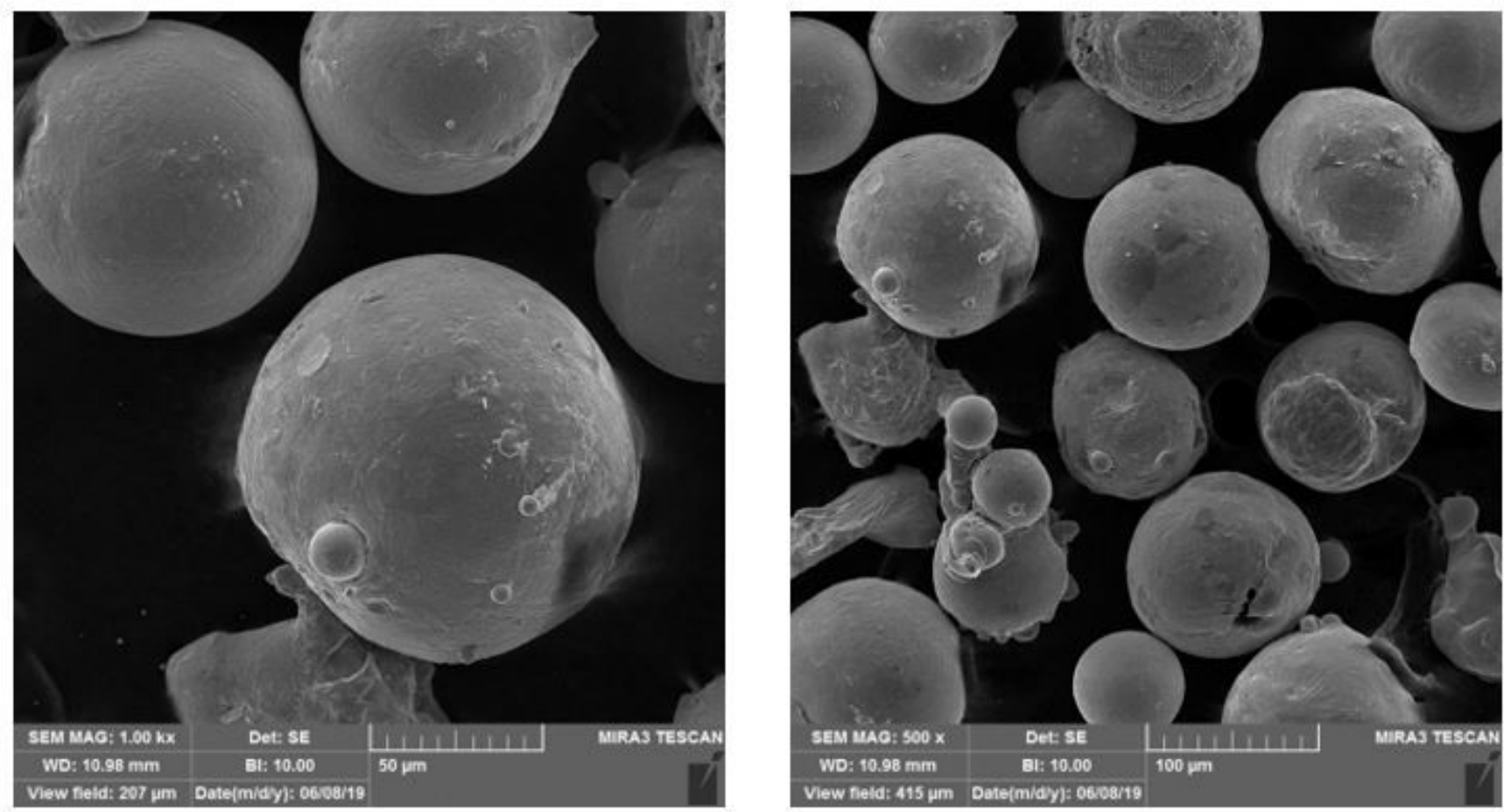

\section{Figure 1}

FESEM of Inconel 718 powder.

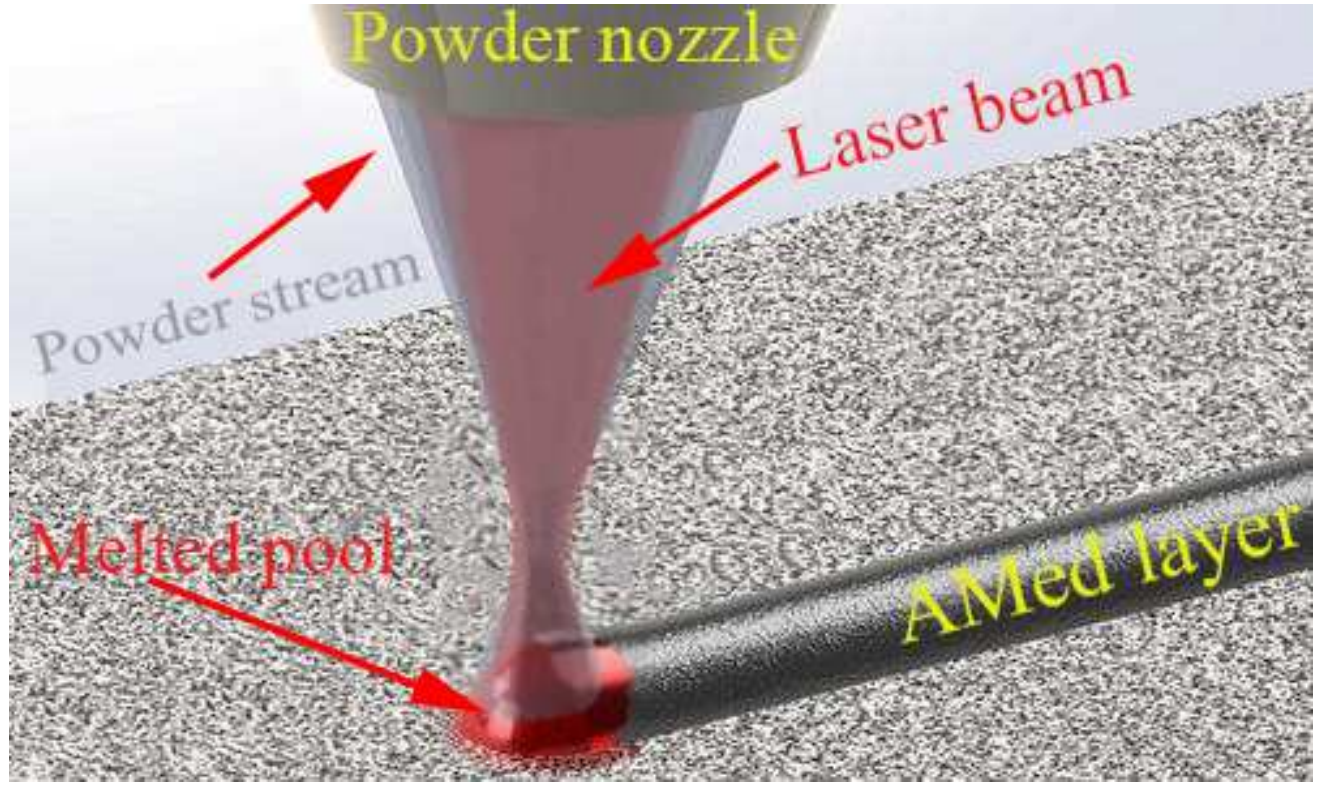

Figure 2

Schematic diagram showing the DLMD configuration [48]. 


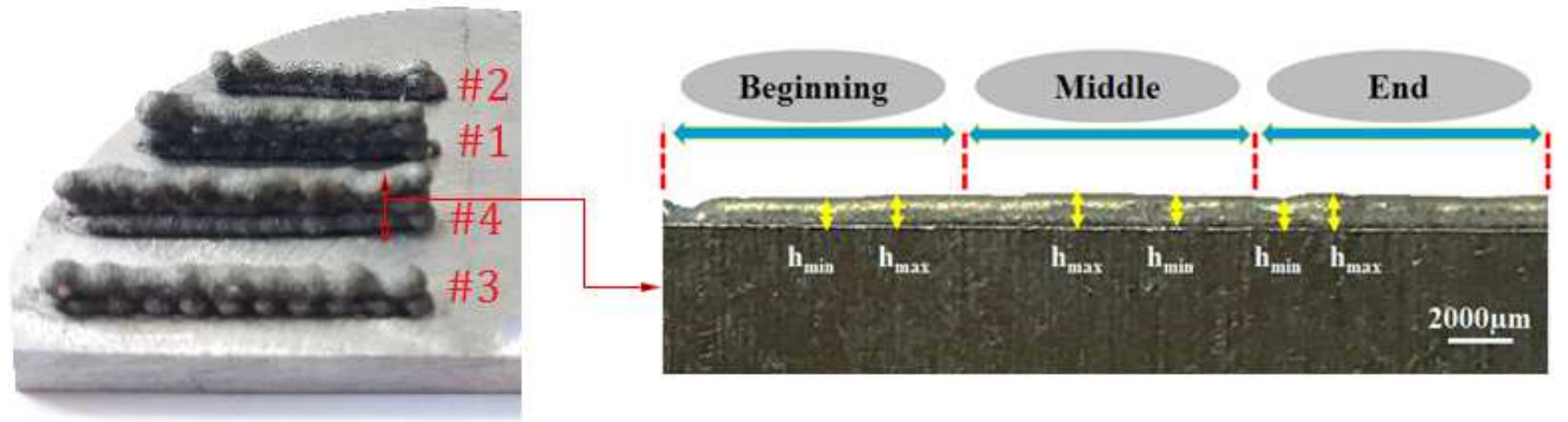

Figure 3

Additively manufactured samples and cross-section of a printed part (thickness of the substrate is $7 \mathrm{~mm}$ )
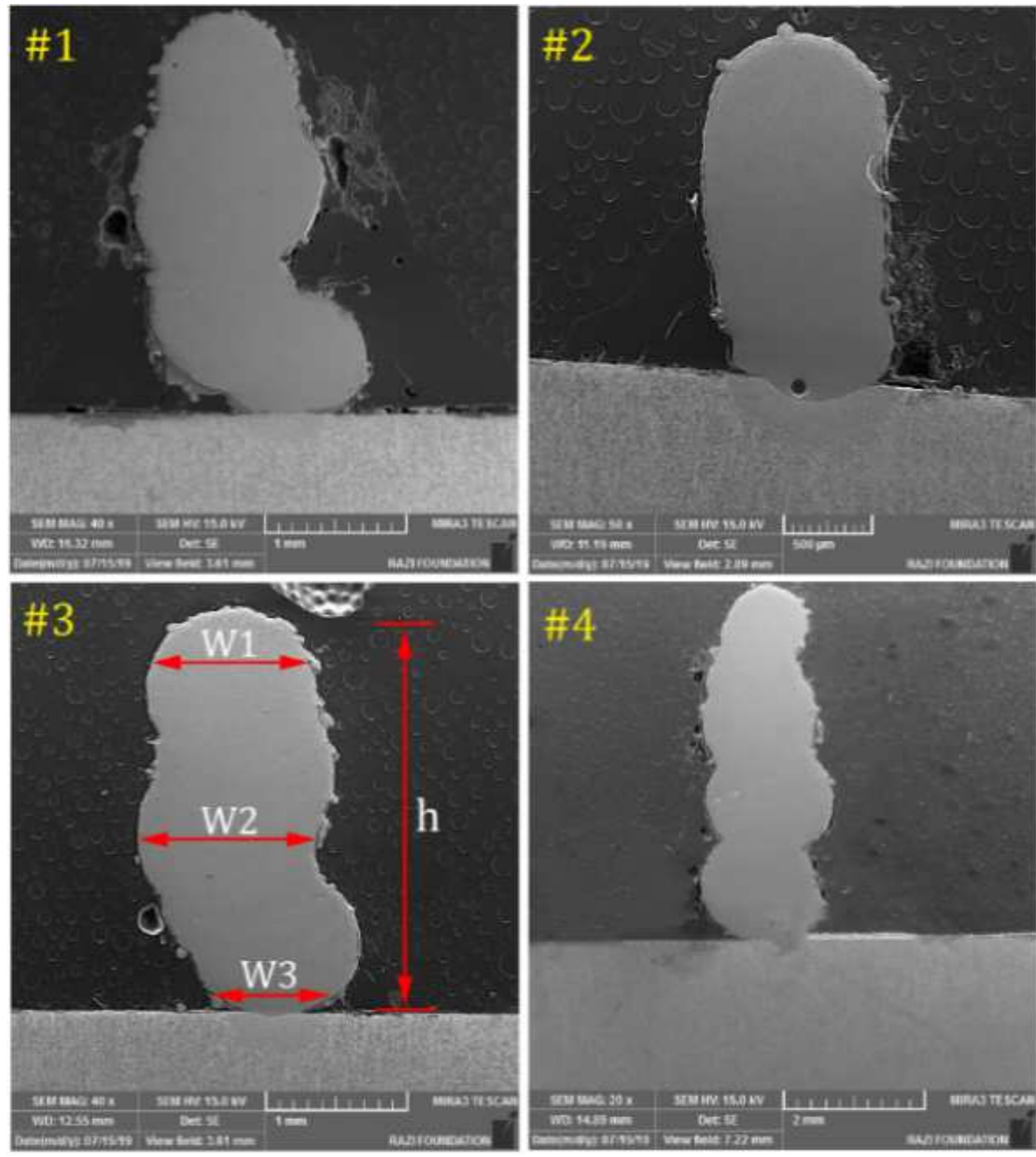
Figure 4

The macro size images of additively manufactured samples

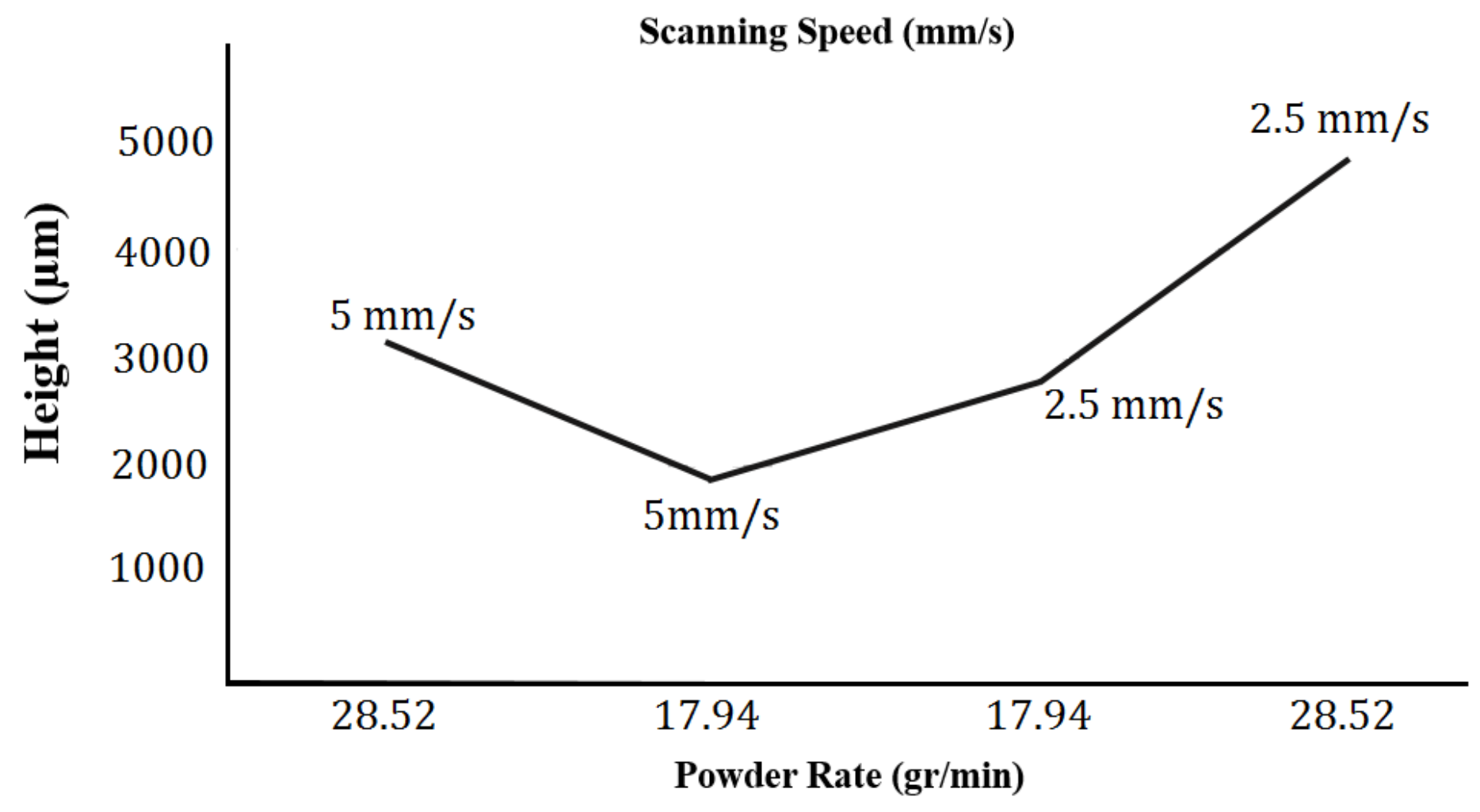

Figure 5

The effect of powder feed rate and scanning speed on wall height.
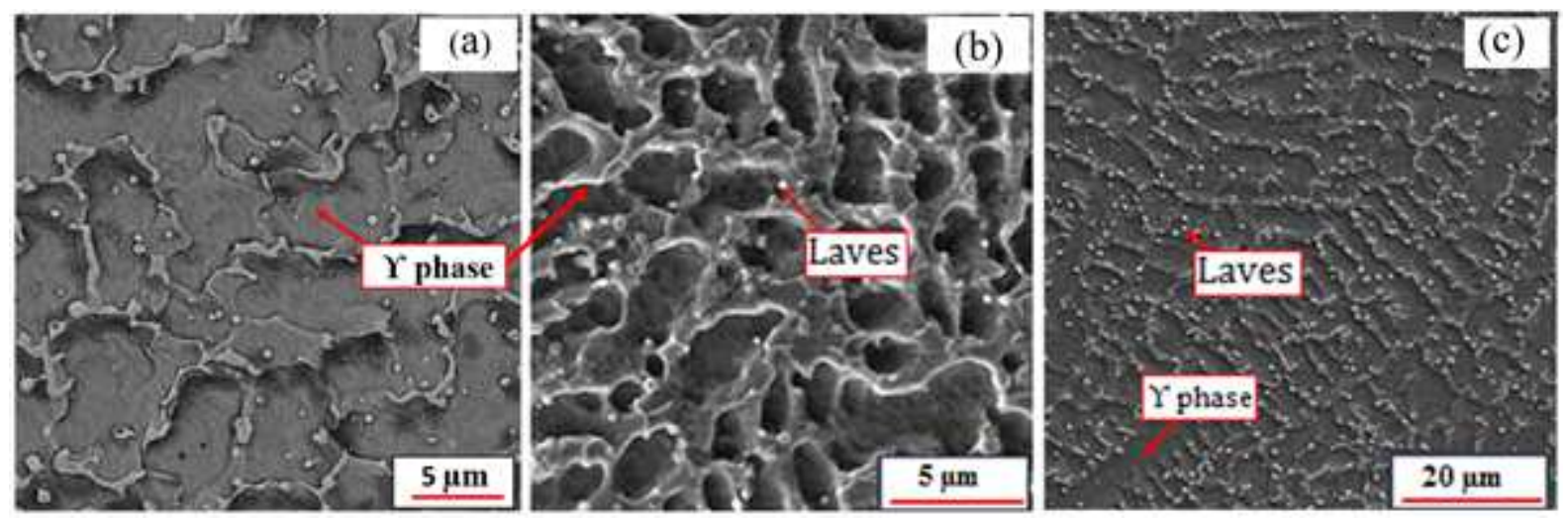

Figure 6

Inconle 718 addetived structure a) y phase b) Y' phase c) Laves phases 

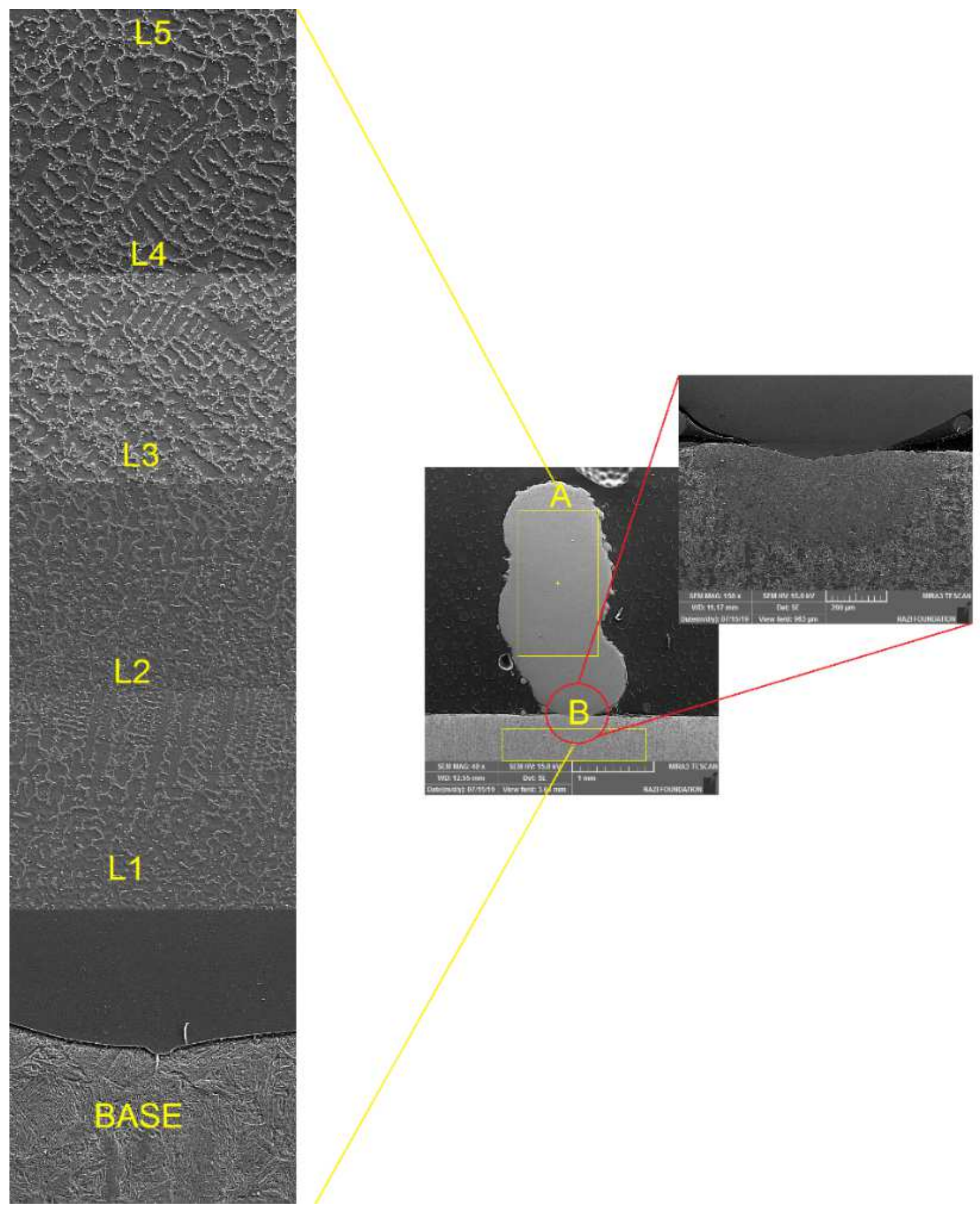

Figure 7

The EDS analysis in 5 layers (L1-L5) of addetived sample \#3 


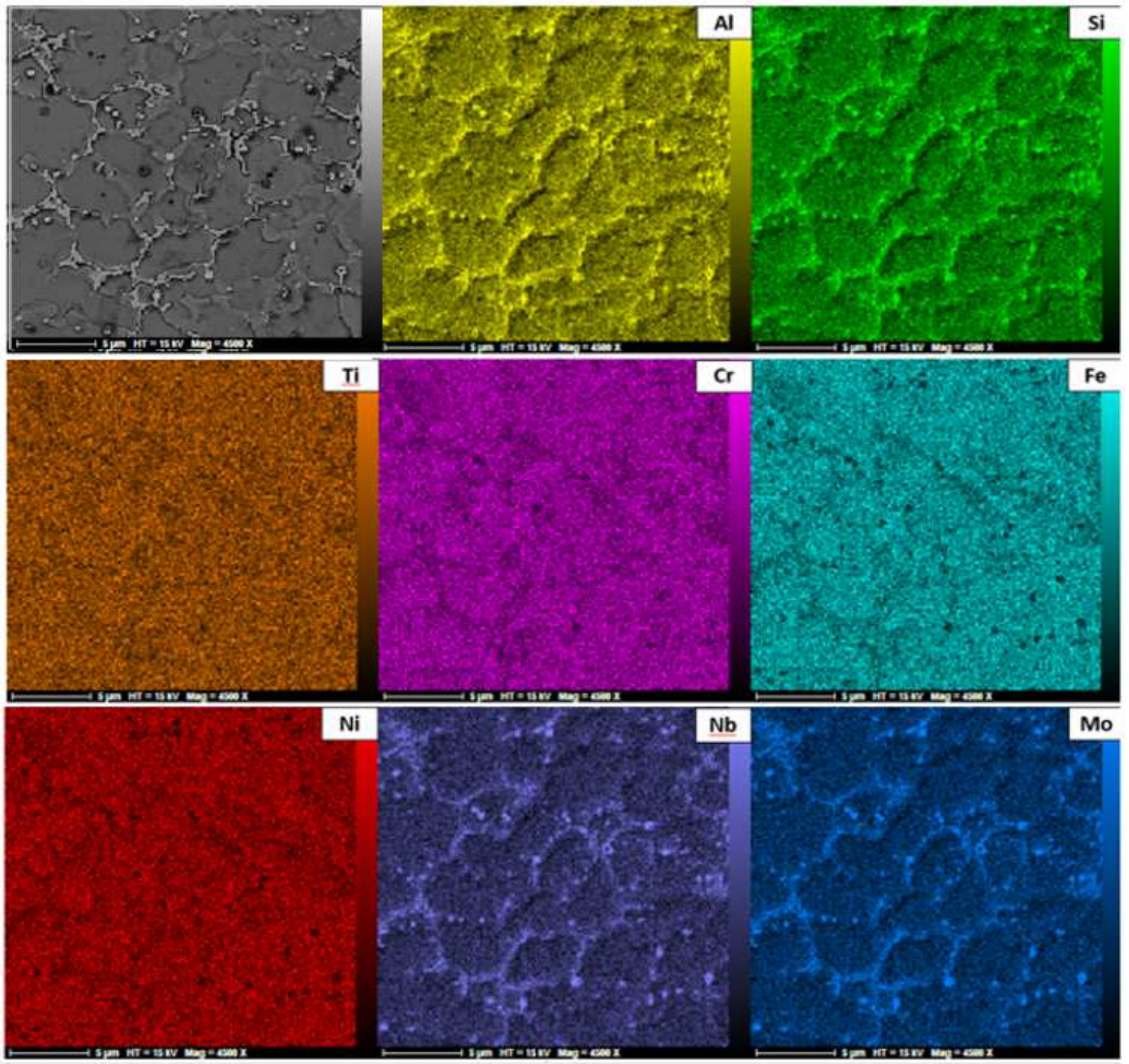

\section{Figure 8}

Map analysis of sample number 4 . 

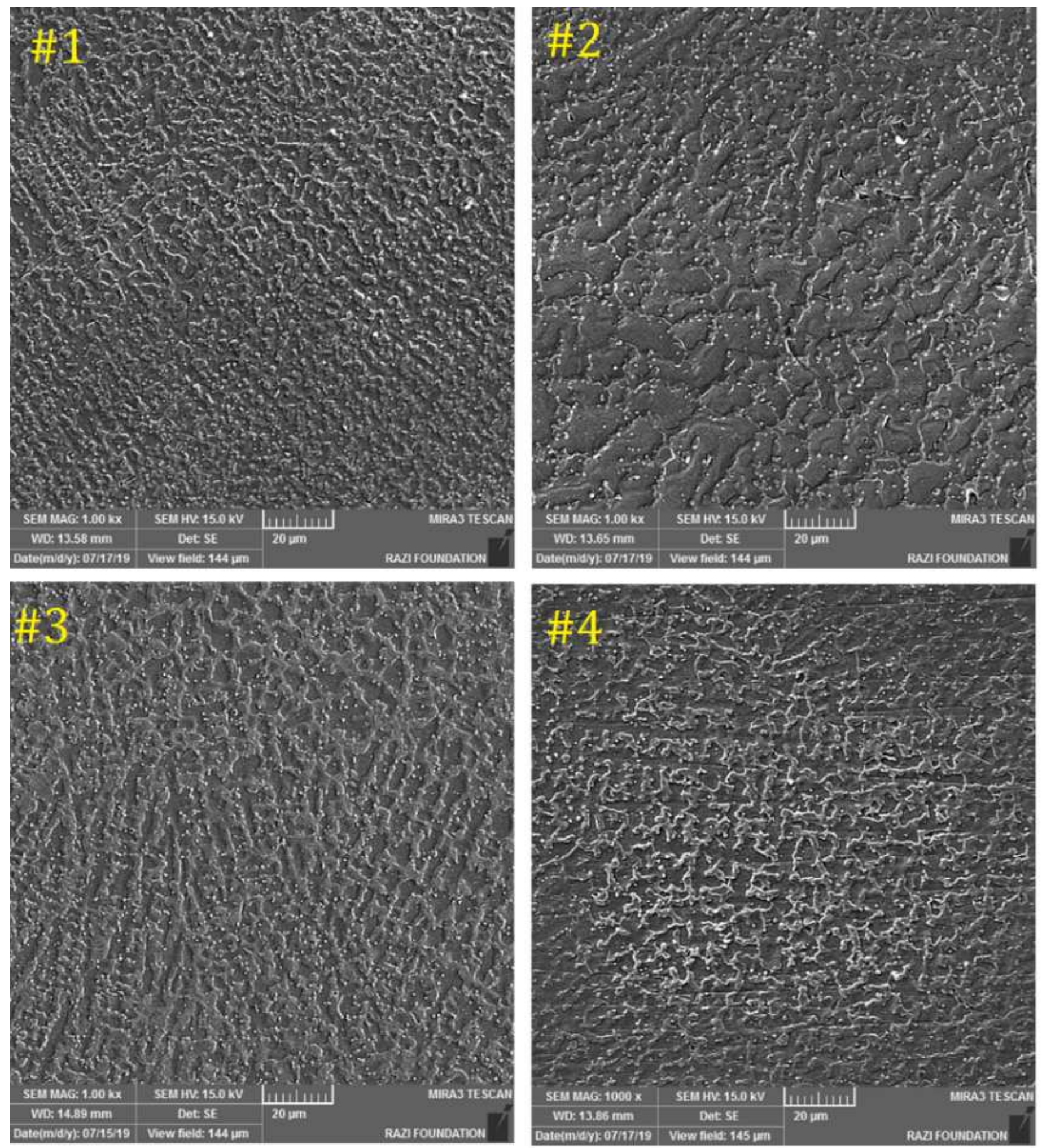

\section{Figure 9}

FE-SEM of samples number 1 to 4 . 


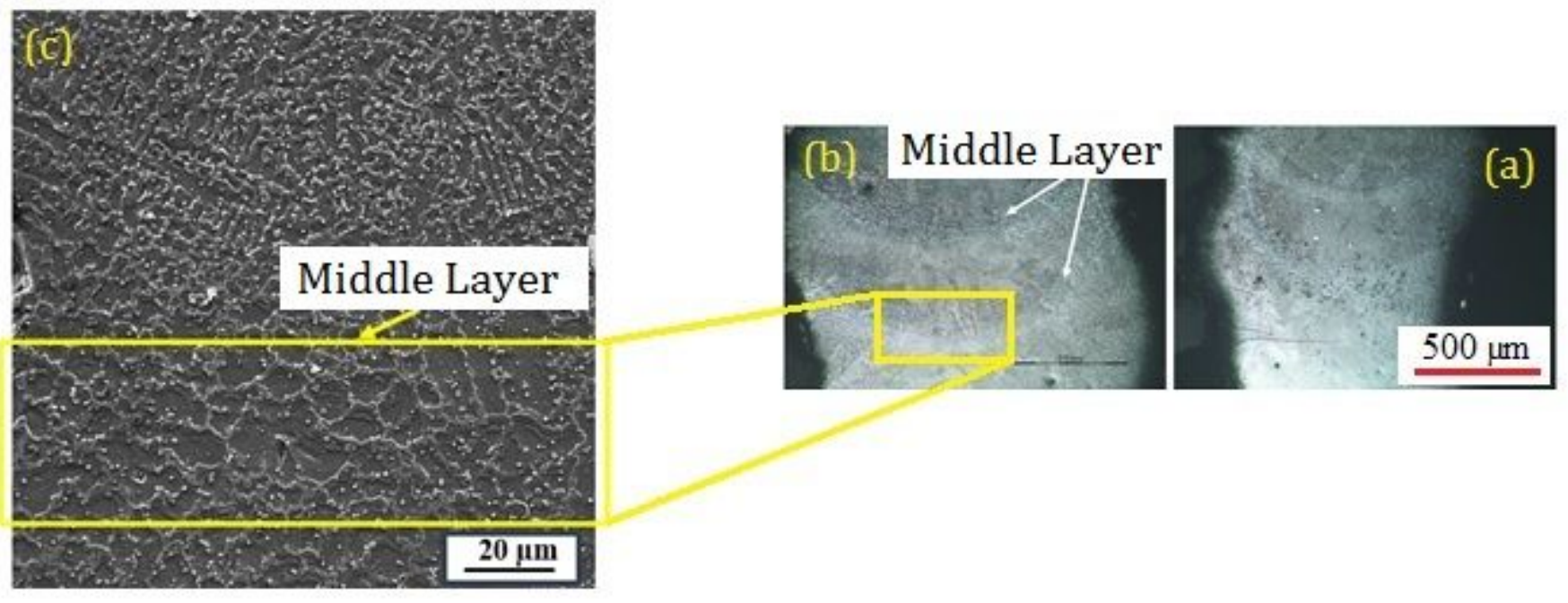

Figure 10

The common boundary between the deposit layers.
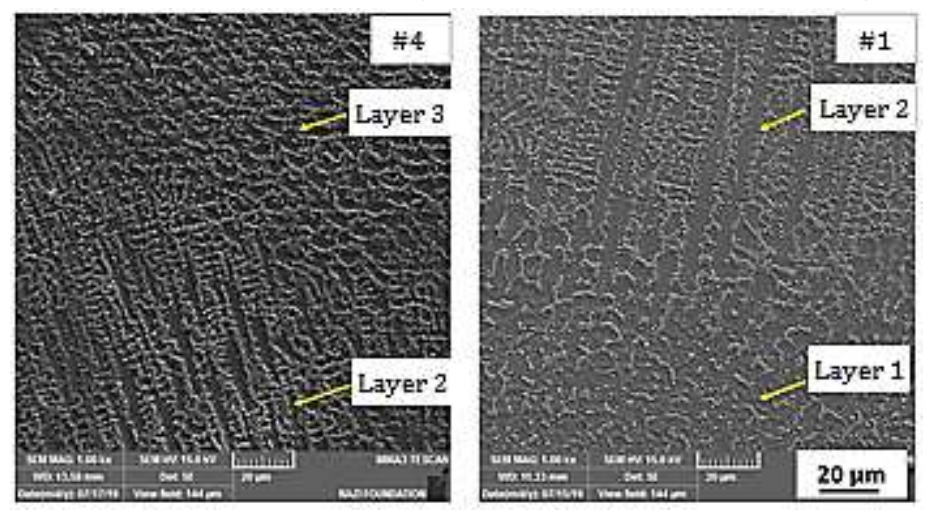

\section{Figure 11}

The common boundary layer of samples number 1 and 4 . 

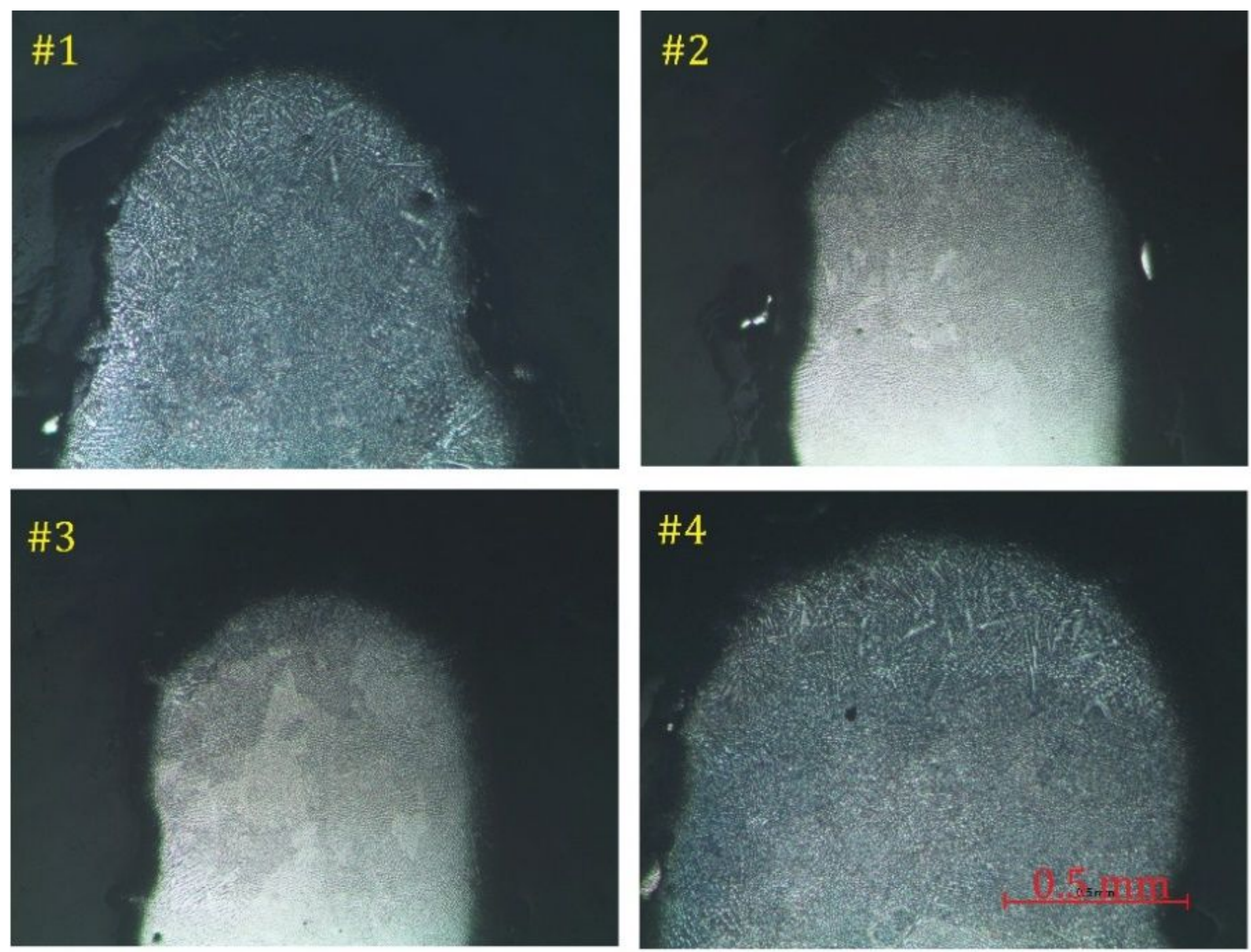

Figure 12

Top section microstructure of the additively manufactured samples for samples \#1 to \#4 

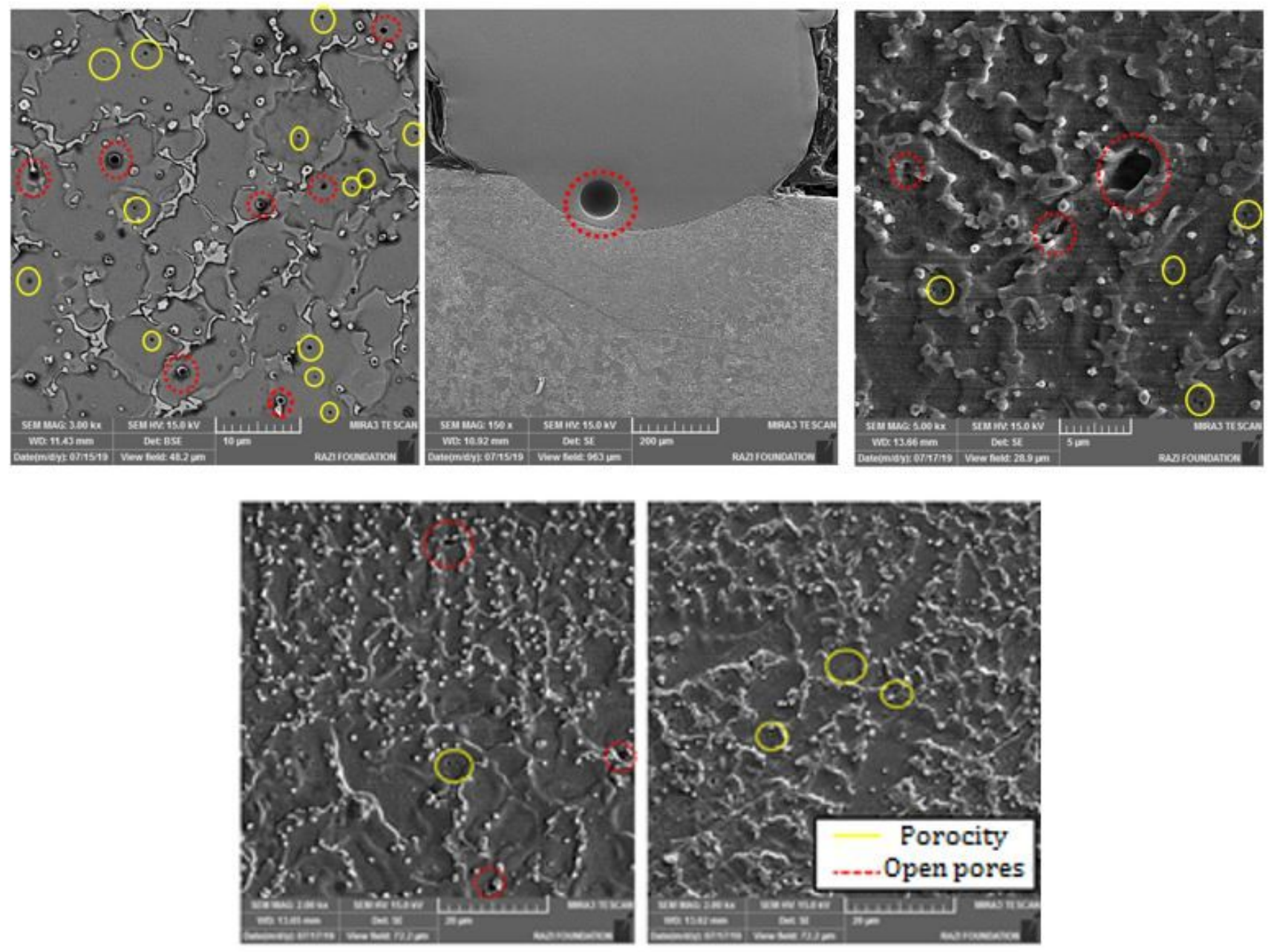

Figure 13

Defects in the microstructure of the addetived samples
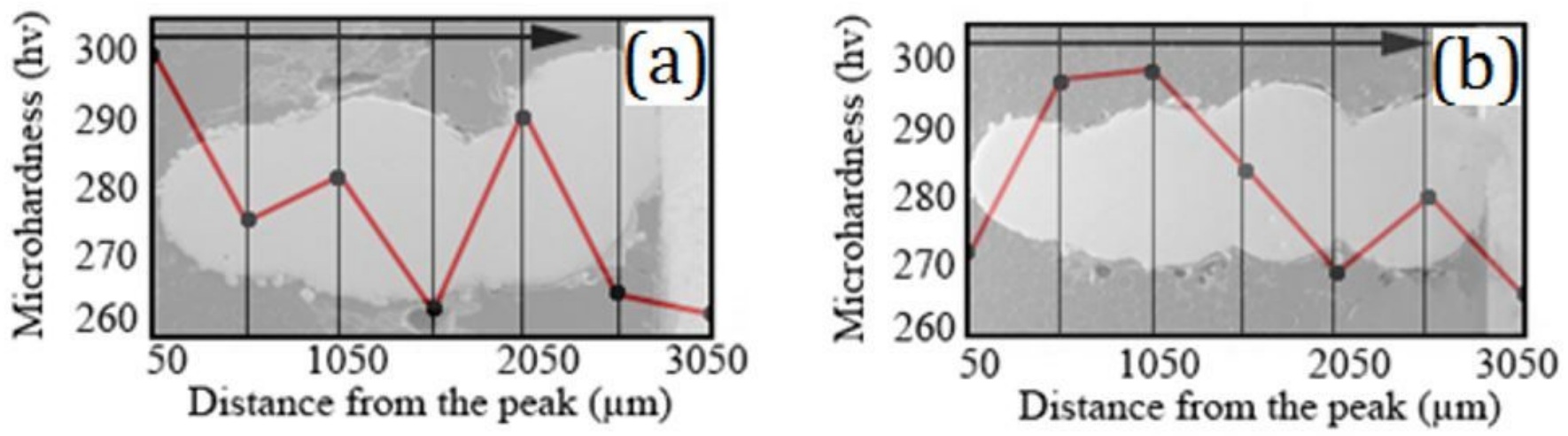

Figure 14

Microhardness of samples a) number 1 and b) number 4 . 